\title{
Kant und die naturwissenschaftliche Erkenntniskritik der Gegenwart. (Mach, Hertz, Stallo, Clifford.)
}

\author{
Von Hans Kleinpeter in Gmunden.
}

Es war der ausgesprochene Zweck des Schöpfers der Kritik der reinen Vernunft; die Philosophie auf jene Stufe strenger Wissenschaftlichkeit zu heben, die er an der damaligen Mathematik und mathematischen Physik $\mathrm{zu}$ bewundern Gelegenheit genommen hatte. Wir wissen, dass er dieselbe für eine unbedingt exakte, ideale in seinem Sinne angesehen hatte, wissen aber auch hente, wie weit die Wissenschaft der damaligen Zeit von diesem Ideale entfernt war, wissen auch, wie sehr es die heutige noch ist, ja sein muss.

Dieser Umstand bietet eine naheliegende und augenscheinlich sehr günstige Handhabe sowohl zur angemessenen Beurteilung der persönlichen Leistung Kants wie auch zu der seiner Lehre überhaupt und ihrer Bedeutung für die Gegenwart.

Denn einerseits lässt es sich doch nicht verkennen, dass das Vorbild der Nathematik und der mathematischen Physik Kant bei seinem Versuche der Rehabilitierung. der Metaphysik als eine Art Zielpunkt vorgeschwebt habe, und dass er sich jederzeit zufrieden und glücklich geschätzt hätte, dasselbe auch nur zu erreichen, wie aus mehreren Stellen seiner Werke wohl zur Genüge hervorgeht; andererseits ist das Niveau der damaligen Mathematik und Naturforschung, die Kant als Muster diente, von der modernen Wissenschaft weit überholt worden.

Ich meine darunter nicht die ungeheure Ausdehnung des Gesichtskreises, die Vertiefung der Methode und : der planmässigen Arleeit überhaupt und die Schar der vielen glïcklichen Entdeckungen, durch welche die moderne Naturwissenschaft ein im Vergleich zu der Unschuld frïherer Zeiten so wesentlich verändertes Gepräge erhalten hatte, - kurz, ich denke gar nicht an das, was in den 
Kant und die naturwissenschaftliche Ërkenntniskritik der Gegenwart. 259

Augen der Laien die Wissenschaft von heute von der vergangener Zeiten in so auffälliger Weise sondert.

Die Auffassung von dem innersten Wesen der Wissenschaft, von ihrer erkenntnistheoretischen Stellung ist es, die im Vergleich zum 18. Jahrhundert eine so gewaltige Änderung erfahren hat. Die Philosophie Kants war ja wohl auf diese Wandlung nicht ganz ohne Einfluss, wenn man sich auch hüten muss, denselben zu überschätzen; ebensowenig war. aber dieser Läuterungsprozess Folge eines andern philosophischen Systems. Auf dem Boden dieser Wissenschaften selbst ist ihre Kritik emporgediehen, sie blieb mit ihrem Inhalt so verwebt, dass durch eine lange Zeit eine Scheidung überhaupt ganz unmöglich blieb.

Die Mathematik eröffnet den Reigen; sie ist es, in die zuerst der kritische Geist eingedrungen war. Die Mathematik des durch Newton und Leibniz inaugurierten Zeitalters vermochte nur äusserst bescheidene Ansprüche auf die Strenge ihrer Wissenschaftlichkeit zu erheben;1) unter dem Eindruck des neuentdeckten Infinitesimalkalküls wurde ohne viel zagende Bedenken frisch drauf los differenziiert und integriert; die kritische Einkehr kam erst, als auf diesem Wege nicht mehr so viele und dabei ziemlich mühelose Ausbeute zu holen war und der gründliche Ausbau eine kritische Durchsicht des kritiklos gesammelten Stoffes erheischte. Dieses Bedürfnis hat sich aber erst zu einer Zeit herausgestellt, als Kants Werk lange vollendet war. Die ersten Anmerkungen dieser Art finden sich in den Schriften von Gauss und dieser war 1777 geboren. Die eigentliche Revision der Grundprinzipien der Mathematik begann aber erst mit Abel und Weierstrass und ist noch heute lange nicht abgeschlossen. Aber auch in ihrer heutigen Gestalt ist sie bereits ausreichend, viele Voraussetzungen Kants als irrig zu erweisen. Dahin gehört namentlich die von der Denknotwendigkeit gewisser geometrischer Grundsätze, ${ }^{2}$ ) die von der Natur des Zahlbegriffes u. m. a.

1) Dies ist schon von Berkeley erkannt worden, was wohl als ein sehr gutes Zeichen der besonderen Schärfe und des ausgezeichneten Verständnisses dieses Philosophen für die exakte Wissenschaft gelten darf.

2) Es mag bei dieser Gelegenheit gestattet sein, auf das ausgezeichnete Werk von D. Hilbert „Die Grundlagen der Geometrie" hinzuweisen, das die logische Untersuchung der Raumanschauung zum Gegenstande hat und in augenfälligster Weise die begriffliche Natur der geometrischen Grundgebilde darthut. 
Viel radikaler war noch die Änderung der Denk- und Sinnesweise, die auf dem Gebiete der erkenntnistheoretischen Auffassung der Naturwissenschaft platzgegriffen hat. Unter dem gewaltigen Eindrucke von Newtons Prinzipien und der andern klassischen Werke mathematisch-physikalischen Inhaltes war ja die Überschiitzung der Bedeutung der Mathematik für die Physik begreiflich. Längere Vertrautheit mit den Arbeitsmethoden der Physik musste es schliesslich aber doch bis zur Evidenz klar machen, dass cine mathematisch abgeleitete Thatsache unmöglich sicherer sein könne, als jene experimentellen, die zum Ausgangspunkt der Ableitung gedient hatten. Die Physik hat den Vorteil, dass alle ihre. Sütze einer experimentellen Prïfung durch zukünftige Erfahrung zugänglich sind; diese Möglichkeit setzt sie vielfach in die Lage, sich auf einfache Weise von der Last eingebildeten Wissens zu befreien. Keiner der Sätze, die Kant für apriorische Grundsätze der Naturwissenschaft ausgegeben hat, vermögen diesen Anspruch heute noch zu wahren und gerade in unsern Tagen untersucht man einen den fundamentalsten derselben, den von der Erhaltung des Stoffes, allen Ernistes in experimenteller Weise auf seine Richtigkeit hin und ist auch geneigt, dieselbe zu bezweifeln. 1) Mögen auch sonst noch die Ansichten über die erkenntnistheoretische Auffassung der Physik auseinander gehen, in diesem Punkte dürfte kaum mehr eine Meinungsverschiedenheit bestehen. Die gesteigerte Kenntnis der Naturkörper und Naturvorgänge hat es bis zur Evidenz erwiesen, dass es in der Natur eine Substanz im philosophischen Sinne des Wortes nicht giebt. Es giebt nichts absolut Beständiges, Unveränderliches, das hat uns zur Genüge die experimentelle Forschung gelehrt. Schon die Thatsache, dass zur Überwachung unserer Masse ein besonderes internationales Bureau eingerichtet werden musste, zeigt dies in angenfälligem Masse. Überall dort, wo die experimentelle Physik die Aufgabe zu lösen hat, möglichst Beständiges herzustellen (wie bei den Massen), hat sie mit den grössten technischen Schwierigkeiten zu kämpfen. An diesem einfachen Beispiel sieht man in geradezu klassischer Weise, wie experimentelle Forschung („rohe Empirie“) im Stande ist, auch auf das philosophische Denken korrigierend einzugreifen. Es ist natürlich hintennach auch leicht, die Art des Fehlschlusses

1) Man vergleiche hierüber die Veröffentlichungen von Landolt und Heydweiller in den "Sitzungsberichten der Berliner Akademie“, den „Annalen für Physik" und der "Physikalischen Zeitschrift", 1901-1903. 
zu konstatieren: Um Veränderungen feststellen zu können, reicht nämlich auch eine nur angenäherte, relative Beständigkeit aus; ausserdem ist es nicht notwendig, dass dieselbe Substanz zu allen Zeiten als Massstab der Veränderung dient. Ein einfaches Thermometer zeigt diese Verhältnisse zur Genüge; crstens dehnt sich nicht nur das Quecksilber, sondern auch das Glas aus, wir haben also keine „Substanz" im logischen Sinne und kömuen die Veräuderung doch messen; zweitens ist ein Thermometer nicht immer und allezeit brauchbar. Mit der Zeit verschiebt sich der Nullpunkt oder es kann auch zerschlagen werden; man nimmt dann einfach ein anderes. ${ }^{1}$ )

Hand in Hand mit der Ausbreitung und Vertiefung der naturwissenschaftlichen Arbeitsmethoden musste auch eine Wandlung in dem Verhältnisse des Naturforschers zur altuiberlieferten Logik vor sich gehen. „Vir Naturforscher kommen tagtïglich wieder in die Lage, bestätigt zu finden, ein wie elendes Werk unsere Schullogik ist“, sagt $\mathrm{H}$ is in seiner Leipziger Rektoratsrede. Wenn das schon ein Anatom findet, wie muss dann erst das Urteil eines Physikers ausfallen! Und das ist ja auch ganz natürlich; Aristoteles hat seine Logik aus dem Wissensinhalte seiner Zeit abstrahiert, und diesen kann man doch mit ziemlich weitgehender Annäherung gleich Null setzen. Das soll natürlich kein Vorwurf gegen die antiken Denker sein, die das Ihrige geleistet haben, wohl aber ein solcher gegen jene, die noch immer die seltsame Ansicht hegen, dass zweitausendjährige Normen für die Beurteilung heutigen Wissens massgebend bleiben sollen. Um es kurz zu sagen: Die Logik steht nicht am Ende, sondern am Beginne ihrer Entwickelung. Leicht möglich, dass zukünftige Zeiten ihre Geschichte mit dem 19. oder 20. Jahrhundert beginuen lassen werden. Man vergleiche doch nur die von Kant benutzte Einteilung der Urteile mit der von Wundt gegebenen und man wird diese Behauptung nicht für übertrieben finden. Nag man letztere nuu für mehr oder weniger gelungen ansehen, das eine ist klar, dass das Subsumptionsurteil, nach dem man das Wesen des Urteils früher beurteilt hatte, nur einen geringen Teil des Urteilsumfanges aus-

1) Die Erfassung dieser einfachen Thatsache scheint auf philosophischer Seite mit besonderen Schwierigkeiten verbunden zu sein; eine rühmliche Ausnahme hiervon macht Paulsen in seinem Kantbuch (S. 192), das überhaupt dem Standpunkt der naturwissenschaftlichen Erkenntniskritik in auffallender Weise gerecht wird. 
macht. Damit werden denn auch die von Kant daraus gezogenen Konsequenzen von selbst hinfällig.

Eudlich lässt sich nach dem ganzen Gange der geschichtlichen Entwickelung nicht verkenuen, dass die Fortschritte, dic unserem Wissen auf physiologischem, experimentell-psychologischem und biologischem Gebiete zu machen vergönnt gewesen sind, auf die Gestaltung des philosophischen Denkens vielfach von bestimmenden Einfluss geworden sind, so wenig auch manche formal logisch veranlagte Denker die "Möglichkeit" eines solchen Einflusses cinzusehen vermögen. ') Es ist ja kein Wissenszweig so von der Gesamtheit unserer wissenschaftlichen Auffassung isoliert, dass er auf dieselbe nicht irgend einen Einfluss auszuüben vermöchte.

Die Voraussetzungen des Kantischen Denkens haben sich also binnen eines Jahrhunderts sehr gründlich geändert; der Begriff einer exakten Wissenschaft ist ein anderer geworden; kein Wunder daher, dass auch der Begriff einer wissenschaftlichen Philosophie sich nicht mehr mit dem der Kantischen Philosophie decken kann.

Es kann keine Frage sein, dass das System Kants in seiner Gesamthcit nicht mehr aufrecht zu erhalten ist; und wenn auch die Zahl der orthodoxen Anhänger Kants - rein statistisch betrachtet - noch keinesweg's ausgestorben ist, so. würde sich eine Auseiuandersetzung mit denselben doch nicht mehr verlohnen. Das schliesst aber natürlich nicht aus, dass Kant Gedanken geäussert, die auch für die Philosophie der Gegenwart noch immer von folgenschwerster Bedeutung sein können. Dadurch erhält aber die Frage nach deren Wesen, Richtigkeit und Bedeutung für die Gegenwart eine besondere Wichtigkeit. Historisch steht Kant im Mittelpunkt der Philosophie; die verschiedensten Denkẹr haben ihre Stellung zu ihm genau zu praecisieren sich bemïht, sie haben dadurch indirekt ihr eigenes philosophisches System charakterisiert und dadurch dem Systeme Kants eine von seinem eigentlichen Werte ganz unabhängige Bedeutung verliehen. Es nimmt gleichsam die Rolle eines gemeinsamen Bezugskörpers, eines Koordinatensystems

1) Aus der Feststellung eines Sachverhaltes, mag derselbe auch auf empirischem Wege erfolgt sein, folgt immer mit Notwendigkeit die Undenkbarkeit seines kontradiktorischen Gegenteiles. Darin liegt hauptsächlich der Einfluss der positiven, wenn auch noch so empirischen, Wissenschaft auf allgemein philosophische Fragen begründet. 
ein, in Bezug auf welches so viele andere Denker ihr System dargestellt haben.

Dieser Sachverhalt giebt der Frage nach dem eigentlichen Sinn des Kantischen Systems eine erhöhte Bedeutung, erschwert aber auch die Beantwortung derselben ganz bedentend. Alle diese Denker haben ja getrachtet, die Auffassung Kants nach Möglichkeit ihrer eigenen anzupassen, d. h. anzudeuten, und so musste denn Kant die verschiedenartigsten Auslegungen über sich ergehen lassen. Daraus entsteht aber für jeden, der den Namen Kants nennt, die Pflicht, sich näher darüber zu äussern, welchen „Kant“ er meine.

Es wird daher auch hier zunächst festgestellt werden müssen, welche Auffassung Kants dem Folgenden zu Grunde gelegt werden wird, d. h. welche Auffassung Kants als die richtige, als Auffassung Kants selbst, betrachtet wird. Der zweite Teil der Abhandlung wird dann auf die Kritik des Kantschen Systems vom Standpunkte der modernen auf dem Boden der exakten Wissenschaften erstandenen Erkenntnistheorie ausgehen, und der dritte jene Gedanken Kants hervorheben, die noch für Philosophie und Wissenschaft der Gegenwart von positiver Bedeutung sind. Dem engern Zwecke dieses Aufsatzes gemäss wird dabei mur das Gebiet der theoretischen Philosophie, namentlich in Bezug auf Mathematik und Naturwissenschaft, zur eigentlichen Behandlung gelangen. Endlich wird an vierter Stelle noch der Fortschritt beleuchtet werden, den die moderne Erkenntnislehre in prinzipieller Richtung über Kant hinaus errungen hat - zum Teile, aber allerdings auch nur zum Teile, in der von Kant angebahnten Richtung.

\section{Die Auffassung des Kantschen Systems vom Standpunlte der naturwissenschaftlichen Erkenntniskritik.}

Die Hervorhebung des Standpunktes der naturwissenschaftlichen Erkenntniskritik hat natürlich nur den Sinn, die hier vorgetragene Auffassung Kants von andern zu unterscheiden, will aber keineswegs besagen, dass dieser Standpunkt für die Beurteilung Kants massgebend sei derart, dass etwa ein anderer Standpunkt notwendig $\mathrm{zu}$ einem andern Ergebnisse führen müsse. Naturgemäss werden allerdings dem naturwissenschaftlich gebildeten Leser Kants andere Umstäñde in erster Linie auffallen als etwa dem Philologen oder dem Ethiker. Nichtsdestoweniger kann 
abor nur Kant selbst für die Beurteilung Kants massgebend bleiben. Man hat zwar dio Sache vielfach so darstellen wollen, als ob sich jede Ansicht aus den Worten Kants herausinterpretieren liesse; wäre dies wirklich der Fall, verlohnte es sich doch wahrlich nicht, sich überhaupt mit Kant abzugeben; wer das thut, desavouiert sich gleichsam selbst. In Wirklichkeit sind die angeblichen Widersprïche doch nicht so gross, wenn auch zugegeben werden muss, dass die Ungenauigkeit des Ausdruckes an manchen Stellen solche zulässt, ja herausfordert. Die Hauptschwierigkeit liegt aber darin, dass das System als solches falsch ist und somit mit der Wahrheit notwendigerweise in Kollision kommen muss. Dann ergiebt sich ein Widerspruch, und je nach der Auffassung des Auslegers wird auch der Ort desselben ein anderer.

Die Intentionen Kants zu erraten, scheint mir aber doch nicht so schwierig, als es nach der Geschichte seiner Erklärungsversuche anzunehmen wäre. Mehr als bei irgend einem Denker ist Kants Gedankenwelt durch seine Ungebung bestimmt; diese, ist aber Dank der regen Kantforschung mehr bekannt geworden als die irgend eines andern Philosophen. Kants Bedeutung ruht viel weniger auf seiner eigenen Originalität als auf der sorgfältigen kritischen Verwertung des zu seiner Zeit vorliegenden, von andern gesammelten Materials. Insofern kann er als Vorläufer der gegenwärtigen wissenschaftlichen Arbeitsweise betrachtet werden, -und vielleicht verdankt er gerade diesem Umstande seine zentrale historische Bedeutung.

Da nun ein sehr wichtiger Teil dieser äusseren Einflüsse, wenn nicht iiberhaupt der wichtigste, der Einfluss der mathematischen Naturphilosophie Newtons') war, so wird eine Beleuchtung von dieser Seite her wohl auch auf das Bild Kants von entscheidendem Einfluss sein müssen.

Indessen haben sich die Kritiker der naturwissenschaftlichen Erkenntnis, die hierbei in erster Linie in Betracht kämen, meist nur im Vorübergehen über Kant geäussert. Dies gilt von $\mathrm{Mach}$, Hertz, Clifford, Stallo und Pearson, in geringerem Masse von H. Cornelius, dessen Ansichten ja gleichfalls zuerst auf naturwissenschaftlichem Boden - wie er selbst hervorhebt, auf Anregungen der Kirchhoffschen Vorlesungen hin - erwachsen sind, und der andererseits ein treffendes Beispiel für eine moderue

1) Auch dieser findet sich bei $\mathrm{Paulsen}$ besonders stark betont. 
Haudhabung Kantscher Gedanken giebt. : So weit Äusserungen der genannten Forscher vorliegen, dürfte sich die hier entwickelte Auffassung mit denselben in Übereinstimmung befinden; zum mindesten erinnere ich mich keiner Behauptung derselben, der ich entgegenzutreten mich bemüssigt sehen würde. Im Gegenteile haben dieselben wesentlich zur Ausbildung und Befestigung der hier vertretenen Auffassung Kants beigetragen; dies gilt hauptsächlich von H. Cornelius ${ }^{1}$ ) und B. Stallo. ${ }^{2}$ )

Von den speziellen Darstellungen der Kantischen Lehre ist es die von Paulsen, der ich vor allen anderen mir bekannten weitaus den Vorzug gebe. In sehr vielen Punkten, insbesondere in der Totalauffassung der Kantschen Persönlichkeit und in dem Verhältnis seiner Lehre zur Physik habe ich geradezu überraschende Übereinstimmungen mit den Ansichten der naturwissenschaftlichen Schule der Erkenntniskritik oder mit meinen eigenen Privatansichten, mit denen in philosophischen Kreisen Anstoss zu erregen ich bereits gewohnt war, gefunden.

In umso schärferen Gegensatz muss ich mich dagegen zu der von Fichte, von Kuno Fischer und insbesondere zu der von der Marburger Schule vertretenen Auffassung Kants stellen. Die Worte, die am Eingange der Kritik der reinen Vernunft -- also an bevorzugtester Stelle stehen - haben für mich durchaus die Bedeutung der bekannten Inschrift an Dantes Höllenthor für jeden Versuch idealistischer Auslegung. Man mag den Begriff des „Dinges an sich" für noch so widerspruchsvoll und ungereimt finden ich werde selbst den härtesten Ausdrücken nicht widersprechen -, hinwegdisputieren kann man ihn aus dem Kantischen Systeme nicht; er bildet gut die Hälfte desselben. Die Behauptung Cohens „das Ding an sich bedeute ihm (Kant) nur eine Stufe und nichts als diese in dem Fortschritt seiner Terminologie von den Kategorien zu den Ideen, von den synthetischeu Grundsätzen zu den regulativen Prinzipien des Zwecks“ muss ich daher als ganz undiskutierbar von vornherein abwcisen.

Ich gehe indes noch weiter. Ich behaupte, so ungehenerlich auch diese Ansicht wohl einem jeden auf den ersten Blick er-

1) „Psychologie als Erfahrungswissenschaft", Leipzig 1897 und insbesondere "Einleitung in die Philosophie“ 1903 (namentlich S. 2:31 ff. und S. 331-334).

2) „Die Begriffe und Theorien der modernen Physik", deutsche Ausgave, Leipzig 1901, S. $241 \mathrm{ff}$. 
scheinen wird, geradezu: Kant war naiver Realist. Die Berechtigung zu diesem Ausspruche stiitze ich auf die Thatsache, dass Kant den Begriff einer objektiven Welt einfach hinnimmt, wie er ilın vorfindet, olne ihn anf seine Berechtigung hin zu priifen. Dass er dies thut, davon sind die oben erwähnten Eingangsworte in die Kritik der reinen Vernunft und die Polemik gegen Berkeley genügende Belege. Dass es ausser uns „Dinge an sich" geben müsse, steht für Kant von vornherein fest; das untersucht er gar nicht. Es ist dies um so auffallender, als vor Kant Berkeley diese Analyse bereits durchgeführt hat; Kant war aber nicht einmal im Stande, sie zu verstehen, was sich allerdings daraus erklären dürfte, dass er Berkeley vielleicht gar nicht durch direkte Lektiire gekannt hat. ${ }^{1}$ ) Wenn man bedenkt, wie schwer hente Philosophen auf ihnen fremde Gedankenkreise eingehen, wird man allerdings diese Annahme nicht für unbedingt nötig halten. Sie drängt sich uns nur deshalb auf, weil es gerade Kants stärkste Seite war, auf anders geartete, seinem eigenen Wesen fremde Betrachtungen einzugehen. In der ganzen Geschichte der Philosophie steht der Fall einzig da, dass ein Mann in diesen Jahren noch auf Einwände von anderer Seite in dieser Weise reagiert hat, wie es Kant in Bezug auf Hume gethan. Aber eben deshalb scheint mir das Missverständnis Berkeleys nur dadurch erklärbar, dass Kant von vornherein in ganz naiver Weise den Begriff einer objektiven Realität als eines Dinges ausser uns gefasst und infolge dessen gar nicht bemerkt hatte, dass Berkeley auf einem andern Wege zum Begriffe der objektiven Realität gelangt war. Kant schien dies eben wegen seines Vorurteiles für ganz unmöglich, er hielt deshalb Berkeleys Ansicht fälschlicherweise für eine „schwärmerische“. Hätte er dieselbe näher kennen gelernt, so wäre ihm wohl ihr Verständnis nicht verschlossen geblieben, so aber hielt or ein näheres Eingehen auf sie .von vornherein für zwecklos.

Ich glaube, dass die Beachtung dieses Umstandes für das Verständnis des ganzen Gedankenganges Kants von fundamentaler

1) Da Kant Königsberg fast nie verlassen hat, scheint es mir doch nicht ausgeschlossen, auf dem Wege der Archivforschung festzustellen, ob Kant Berkeley überhaupt gekannt hat. Hat es zu Kants Zeiten in Königsberg kein Exemplar der Berkeleyschen Schriften gegeben, so konnte auch Kant in dieselben keine Einsicht nehmen, im gegenteiligen Falle wäre es aber zum mindesten sehr wahrscheinlich, dass Kant Berkeley wirklich gelesen hat. Für die Beurteilung Kants wäre die Entscheidung dieser Frage wohl von grosser Bedeutung. 
Bedeutung ist. Kant ist Dualist, Dinge auf der einen Seite, das Subjekt, auf der andern stehen ihm von vornherein fest; was er sucht, ist die Brücke, die von dem einen Teil zum andern hinüberführt. Man hat Kant vorgeworfen, dass die Aufstellung des Begriffes „Ding an sich" ein Verstoss gegen seine eigene Kallsalitätstheorie war. Mit Paulsen entgegne ich hierauf, dass dies nicht der Fall (S. 157 f.), und dass ein eigentlicher Widerspruch, wenn man sich auf den Boden des Kantschen Systems stellt, nicht vorhanden ist. Freilich ist der Begriff eines „Dinges an sich" ein widersprechender und führt nachträglich zu Unzuträglichkeiten; er ist eben kein geprüfter, sondern ein "naturalistischer" Begriff nach der Terminologie ron Cornelius.

Ich meine natürlich nicht, dass Kant naiver Realist in dem Sinne war, dass er die Sinnesqualitäten hypostasiert hätte, er macht vielmehr gegenüber Locke den Fortschritt, dass er auch die subjektive Natur der primären Qualitäten auerkennt; aber die naive Grundannahme des letzteren von der Existenz von Dingen behält er dennoch bei. Überhaupt ist der Unterschied zwischen Locke und Kant nicht gar so gross, als er gewöhnlich ausgegeben wird. Der „Versuch über den menschlichen Verstand" enthält im regellosen Nebeneinander fast das ganze Material der Vernunftkritik in den Teilen, die ihren positiven Aufbau ausmachen. Sehr mit Recht bemerkt Paulsen, dass Locke eben nicht nach dem ersten Buche beurteilt werden dürfe, das - wie man wohl sagen kann - ja in Wirklichkeit eigentlich nur Wortstreitigkeiten enthält.

Dadurch, das Kant „Ding an sich" und „Subjekt" einander gegenübersetzt, entsteht für ihn die Frage nach der Möglichkeit ${ }^{1}$ ) der Erkenntnis. In der Setzung und Lösung dieser Frage erblickt er selbst die klassische Leistung seines Lebens. Das ist es, was ihn in grundsätzlicher Weise von der überkommenen Metaphysik seines Zeitalters scheidet, die sich diese Frage gar nicht hatte beifallen lassen. Insofern besteht also allerdings ein radikaler Gegensatz, und es ist sicherlich nicht, wie Paulsen meint, der Umstand allein, dass die Leibniz-Wolffsche Philosophie

1) Auf idealistischer Grundlage verliert diese Fragestellung ihren Sinn; ein Problem liegt eben nur dann vor, wenn Subjekt und Ding an sich toto genere verschieden sind. Fụ̈r den Standpunkt Berkeleys oder Machs aber auch für den der idealistischen Metaplıysik besteht daher dieses Problem gar nicht. 
die Kant nähere war, daran Schuld, dass er den Gegensatz gegen dicselbe so scharf betont hat.

Darauf beschränkt sich aber auch allerdings der Gegensatz gegen dic üborlieferte Metaphysik. Er ist kein Gegensatz gegen dic "Metaphysil"“ als solche, deren wärmster Anhänger Kant zeitlebens geblieben war, sondern nur gegenn die bisherige Art ihrer Begrïndung. Gewiss hat wieder Paulsen Recht, wenn er mit gesperrten Lettern verkündet: „Das Ziel aller Bemühungen Kants ist dic Begrïndung einer wissenschaftlich haltbaren Metaphysik nach neuer Methode." Alles in allem genommen ist auch der Gegensatz gegen Leibniz, wenn auch in einer Richtung ein fundamentaler, so doch kein durchgreifender; Leibniz' Monaden erinnern z. B. schon an die "Dinge an sich", und in den sonstigen Anschauungen herrscht vielfache und sehr weitgehende Übereinstimmung. Es ist eben nur die Anregung Humes gewesen, die die Abweichung vom bisherigen Systeme bewirkte. Sie wirkte aber nur als Anregung, als auslösender Funke; auf die Art der nell einsetzenden Kantischen Gedankenbildung hatte das Humesche Denken keinen Eínfluss; für sie blieb der Rationalismus des Zeitalters massgebend.

Die erste Antwort auf die Frage nach der Möglichkeit der Erkenntnis musste natürlicherweise lauten: Die Dinge an sich sind als solche unerkenubar.

Aber bei diesem allerdings unvermeidlichen Ergebnis blieb Kant nicht stehen; das Beispiel der Nathematik und der mathematischen Naturwissenschaften war ihm ein Fingerzeig für die Möglichkeit der Erzielung eines positiven Resultates. Er stellte sich daher die Frage nach der Art des Zustandekommens dessen, was als Erkenntnis auftritt und insoferne mag er seine Philosophie eine kritische genannt haben. Da kam ihn denn der „kopernikanische" Gedanke, ob sich- denn nicht etwa die "Gegenstände" nach unserer Erkenntnis richten. Die Dinge an sich erkennen wir nicht; das, was wir erkennen, musste daher einen anderen Namen erhalten, den der „Erscheinungswelt“. In Bezug auf die Gegenstände der Erscheinung ist nun Kant Idealist, indem er dieselben wenigstens ihrer „Form" nach durch die erkenntnisschaffenden Kräfte des Subjektes zustande kommen lässt. Unsere Erkenntnis beginne zwar erst mit der Erfahrung, aber das hindere offenbar nicht, dass bei der Entstehung der letzteren ein subjektiver Faktor massgebend sei, der dieselbe mitbedingt. Dieser 
Faktor ist offenbar von jeder Erfahrung insofern unabhängig, als er nicht erst nachträglich, a posteriori, durch Erfahrung entsteht, sondern schon bei einer jeden Erfahrung, auch der ersten, von vornherein a priori nitbeteiligt ist. Dass er etwa vor jeder Erfahrung bereits eine selbständige Existenz führe, ist deshalb anzınehmen nicht notwendig; die genetische Theorie ist mit Kants Ansicht ebenso verträglich wie die nativistische. Genug an dem, dass bei einem jeden Erwerb von Erfahrungen ein Faktor beteiligt ist, der keine Folge vorangegangener Erfahrungen ist. Es ist hingegen sehr wohl damit vereinbar anzunehmen, dass die physische Organisation auf die Entwickelung der apriorischen Funktion vou Einfluss sei; was allein Kant behauptet, ist, dass es keine Erfahrungen giebt, die ohne Zuthun eines subjektiven, ron der Erfahrung selbst unabhängigen Faktors zustande kommen.

In der Aufstellung dieses Apriori unterscheidet sich nun Kant noch gar nicht von Locke, der ja als der erste die Thätigkeiten des menschlichen Geistes registriert hatte und hierdurch das Naterial für diesen Teil der Vernunftkritik grösstenteils herbeigeschafft hatte. Lockes Versuch hat allerdings in der Klassifikation und Anordnung der Thatsachen grosse Mängel; ja man kann von einer "Ordnung" kaum sprechen. Die Darstellung ist cine durchaus unwissenschaftliche; aber allerdings hatte Locke eine solche gar nicht beabsichtigt; was er giebt, sind wirklich nur zufälligerweise zusammengeraffte Bruchstücke - freilich solche von grösstem inhaltlichen Werte. Lockes „Versuch" erfuhr aber durch die "Nouveaux essais" von Leibniz eine Beleuchtung, welche diese Mängel wesentlich schwinden liess und dadurch, wie Vaihinger hervorhebt, für die Vernunftkritik von grösster Bedeutung geworden ist.

Indessen tritt gegenüber Locke bei Kant doch ein wesentlich neuer, wie es scheint, ihm ureigenster Gedanke auf. Locke findet das Apriori auf empiristischem Wege, durch Selbstbeobachtung; seine Methode gründet sich also auf empirische Psychologie. Kant konnte eine solche Methode nicht brauchen, er war auf der Suche nach unbedingt und allgemein giltigem Wissen, der Weg Lockes konnte ihm ein solches nie bieten. Die Methode, die Kant gefunden, ist die transscendentale, sie beruht auf der Aufsuchung der Bedingungen, unter denen Erkenntnis überhaupt zustande kommen könne. Zeigt es sich, dass zur Entstehung von Erkenntnis diese oder jene Annahme über die Beschaffenheit unserer Geisteskrüfte 
unumgänglich notwendig ist, so sehen wir uns genötigt, dieselbe als eine notwendige Bedingung von Erkenntnis überhaupt anzunehmen. Auf diese Weise glaubte Kant einen rein logischen IVeg zur Entleckung von psychischen Thatsachen gefunden zu haben. ${ }^{1}$ )

Die Erfahrung war Kant infolgedessen immer das Produkt zweier Faktoren, der Erkenntniskräfte des Subjektes, die als solche ausserhalb der Erfahrung standen und nicht etwa als durch innere Erfalırung direkt gegeben betrachtet werden konnten, und eines zweiten Falktor's, der die "Naterie“ der Empfindung beisteuerte und als dem Subjekt fremd gegenüberstehend, für dasselbe eine zufällige Bedeutung hatte; d. h. das, was dieser Faktor beisteuerte, trat dem Subjekte immer in der Rolle eines ihm fremden Elements gegenüber, es war eben ganz zufällig, was gerade die Materie einer Empfindung ausmachte. Diesen Faktor hat Kant nicht weiter verfolgt.

Unter diesem Gesichtspunkte erscheint es ganz erklärlich, dass Kant die äussere und die innere Erfahrung völlig gleichwertig. erschienen $;^{2}$ ) bei beiden war eben ein Faktor beteiligt, der zur Erfahrung hinzukan und von derselben ganz unabhängig war, und ein zweiter, der dem Subjekte als zufällig erscheinen musste. Erfalırung heisst bei Kant das, was uns die Thätigkeit unseres Geistes lehrt, die selbst nicht Gegenstand der Erfahrung sein kaun.

Den Nachweis von der Existenz und Art dieser schaffenden, gesetzgebenden Thätigkeit des Ich hat nun Kant in zwei Teilen geführt: in der transscendentalen Ästhetik und Analytik.

Der Beweisgang ist in beiden Fällen etwas verschieden. In der Ästhetik tritt der eigentliche transscendentale Beweisgang, wie Paulsen (S. 160) hervorhebt, sehr merklich zurück, indem erst in der zweiten Auflage der Vernunftkritik demselben wenigstens besondere Paragraphen gewidmet sind, während in beiden ihm die „metaphysische Deduktion“ vorangestellt ist. Es dürfte dies eben,

1) Es șagt allerdings schon Locke: „Für meinen dermaligen Kweck wird es genügen, die Erkenntnisfähigkeiten des Menschen insoweit in Betracht zu ziehen, als sie auf die Gegenstände, mit denen sie zu thun haben, angewendet werden" (Versuch, I, 1, § 2). Das ist eigentlich schon der Standpunkt der transscendentalen Methode Kants.

2) Beziehungsweise die äussere Erfahrung' wegen der Ermöglichung mathematischer Betrachtungsweise als die yollkommenere galt. 
Kant und die naturwissenschaftliche Erkenntniskritik der Gegènwart. 271

wie Paulsen bemerkt, davon herrühren, dass die Lehre von der Idealität des Raumes. und der Zeit ein älteres Bestandstück des Kantischen Systems gebildet hat. Offenbar erschien Kant auch die metaphysische Deduktion als die weit leichtere Arbeit gegenüber der transscendentalen, wenigstens hebt er die Mühe, die ihm die transscendentale Deduktion der Verstandesbegriffe gemacht hat, besonders hervor.

Jedenfalls glaubte Kant durch die Untersuchung der Bedingungen, unter denen Erkenntnis möglich ist, gezeigt zu haben, wieso der menschliche Geist in der That im Stande ist, auf dem Gebiete der Mathematik und der allgemeinen Naturwissenschaft ein Wissen a priori zu erzeugen. Damit hatte Kant den zweiten Teil seiner Antwort auf die Grundfrage nach der Möglichkeit der Erkenntnis gegeben und dieser ist bereits wesentlich metaphysischer Natur, wenngleich diese Metaphysik noch einen wesentlich immanenten Charakter besitzt; sie bezieht sich nur auf die Erscheinungswelt, bezw. auf die Mathematik und Naturwissenschaft.

Kant hat aber noch eine dritte Antwort auf diese Grundfrage gegeben, die sich auf die Metaphysik im engern Sinne des Wortes bezieht. Er hat durch das Aufheben des Wissens von metaphysischen Gegenständen im bisherigen Sinne auch die (von Hume u. a. behauptete) Unmöglichkeit derselben als unbeweisbar dargethan, d. h. er hat zunächst durch die Aufhebung des Wissens Raum für den Glauben geschaffen - das war das Ergebnis der Kritik der spekulativen Vernunft. In ähnlicher Weise wie in der Kritik der reinen Vernunft das Bestehen der Mathematik und mathematischen Physik den Aufbau einleitet, geht Kant in der Kritik der praktischen Vernunft von dem als Axiom hingenommenen allgemeinen Vorhandensein des Sittengesetzes aus und untersucht wieder in ganz analoger Weise die Gründe seiner Möglichkeit. Und das führte ihn dann auf seine Weise zu einer,positiven Beantwortung der Grundfragen der Metaphysik, die freilich von der hergebrachten verschieden ist und sich auch von dem Wissen auf dem Gebiete der Erscheinungswelt unterscheidet, für den eigentlichen Zweck aller Netaphysik dieser Art aber vollkommen ausreichend ist.

Zusammenfassend lässt sich also sagen: Kant ist Dualist, die Existenz von Dingen an sich im Sinne des naiven Realismus steht ihm von vornherein fest, deshalb entsteht für ihn die Frage nach 
der Müglichkeit der Erkenntnis. Er giebt drei Antworten auf dieselbe; die Erkennbarkeit der Dinge an sich ist uns als solche verschlossen; aber wir sind im stande, wenn nicht die Dinge, so doch die Fischeinung der Dinge zu erkennen und zwar zum Teile allch a priori; wir kïnnen ferncr nit Recht auf die Existenz der metaphysischen Ideen von Freiheit, Gott und Unsterblichkeit schliessen, wenn wir sic auch nicht gleich den Gegenständen der Erscheinungswelt zu erkennen vermögen. Unser Wissen von der Erscheinungswelt basiert auf der Thatsache, dass wir an der Entstehung derselben selbst aktiv beteiligt sind; und diese. Thatsache ist eine logisch notwendige, weil ohne sie derlei wie Erfahrung gar nicht zu Staude kommen könnte.

In der Aufstellung dieser Positionen glaube ich das Wesentliche des Kantischen Gedankenganges seinen eigenen Intentionen gemäss zur Darstellung gebracht zu haben; es folgt nun die Kritik desselben.

\section{Die Beurteilung des Kantischen Systems vom Standpunkte}

\section{der heutigen naturwissenschaftlichen Erkenntniskritik.}

Die wesentlichen Fortschritte, welche die exakten Wissenschaften seit Kants Zeiten in erkenntnistheoretischer Beziehung gemacht haben, - mit Recht bezeichnet deshalb Al. Riehl unser Zeitalter als ein wahrhaft philosophisches - lassen die Beantwortung der Frage nach dem gegenwärtigen inhaltlichen Werte der Kantischen Ideenwelt verhältnismässig leicht erscheinen.

Das Grundprinzip aller exakten Wissenschaft, gleichsam die Definition der Exaktheit ist die Forderung, keine Annahme ungeprïft hinzunehmen, sondern jede zuvor auf ihre Berechtigung hin sorgfältig zu untersuchen. Die Systeme früherer Denker zeigen die für sie charakteristische Eigentïmlichkeit, dass sie Annahmen in ihre Entwicklungen einfliessen lassen, dereu sie sich gar nicht bewusst werden. In Übereinstimmung mit Mach, Stallo, Clifford und Cornelius, der in seiner „Einleitung in die Philosophie“ diesen Gesichtspunkt in sehr treffender Weise der historischen Betrachtung. der philosophischen Systeme zu Grunde gelegt hat, nenne ich ein solches Verfahren ein metaphysisches. Dasselbe ist durchaus nicht 
auf die Philosophie allein beschränkt; es giebt auch eine Metaphysik in der Naturwissenschaft und Mathematik. ${ }^{1}$ )

Es kamn nun keine Frage sein, dass auch Kant durch seine Aufstellung des „Begriffes“ - wenn man überhaupt so reden darf - vom Ding an sich dem Vorwurf metaphysischer Gedankendichtung verfällt. In vorigen Abschnitte glaube ich zur Genüge dargethan zu haben, dass das Ding an sich ein unveräusserliches Bestandstück des Kantischen Denkens bildet, und derjenige, der nach dem Vorgange von Fichte dasselbe wegdeuten möchte, das System völlig missversteht, wie ja auch Kant selbst ausdrücklich festgestellt hat. Andererseits ist nun das Ding an sich erstens eine unerwiesene Hypothese und zweitens ein "Begriff“, der überhaupt kein Begriff ist und daher in einer exakten Wissenschaft keine Stelle einnehmen darf. Das Ding an sich ist eine blosse Hypothese, denn es ist uns nicht gegeben; was uns gegeben ist, sind bloss die „Farben, Töne, Wärmen, Drücke, Räume,Zeitenu.s. w.,“2) d. h. die Elemente unseres Bewusstseins. Kant erschien das Ding an sich als ein notwendiger Rückschluss hieraus, der aber nicht als stichhaltig betrachtet werden kann. Was sich vom Standpunkte der strengen Wissenschaft aus sagen lässt, ist nur, dass ein Teil dieser „Ideen“ uns aufgenötigt wird. Wenn nun Berkeley als Ursache dessen den Willen Gottes angiebt, so macht er sich zwar gleichfalls einer metaphysischen Annahme schuldig, vermeidet aber doch Kants Fehler, einen undenkbaren Begriff einzuführen; ja er kann für seine Hypothese sich auf die Prinzipien der naturwissenschaftlichen Forschungsweise stützen, die das Unbekannte durch das Bekannte zu erklären gebietet. Es kann eben Berkeley zu seinen Gunsten anführen, dass der Schluss auf die Existenz fremden Bewusstseins, der doch tagtäglich gemacht wird, ohne Bedenken zu erregen, von genau derselben logischen Art ist. Damit hat denn Berkeley seinen Zweck, die Führung eines Gottesbeweises auf unendlich einfachere Art erreicht als Kant und kann sich schun einigen Spott über die „Gelehrten" erlauben.

1) Vgl. die systematische Entwickelung dieses Gedankens bei B.Stallo, "Die Begriffe und Theorien der modernen Physik", Leipzig 1901.

2) Mach, Die Analyse der Empfindungen, S.1. Ganz so beginnen auch Berkeley, Abhandlung über die Prinzipien der menschlichen Erkenntnis und W. K. Clifford, Von der Natur der Dinge an sich (Mind, 1878, deutsche Ausgabe Leipzig, Barth 1903). Richtiger ist allerdings zu sagen, dass nur Komplexe dieser Elemente und nicht diese selbst unmittelbar gegeben sind, wie dies Cornelius thut. 
Wie Clifford eingangs der bereits zitierten Schrift mit grosser Prizision hervorhebt, ist der Ausgangspunkt Berkeleys (u. Machs) unanfechtbar. Eine zweite Frage ist die, ob ein Auskommen ohne Hinzunahme einer Hypothese, also eine wahrhaft metaphysikfreie Wissenschaft möglich ist oder nicht, und ob etwa im zweiten Falle die Hypothese Berkeleys anzunehmen ist.

Kants Ding an sich hat den zweiten Fehler, dass es als undenkbarer Begriff notwendigerweise zu Widersprüchen führen muss. Hat nämlich Kant zuerst geschlossen: was nicht subjektiv willkürlich ist, muss einen objektiveu Ursprung haben, so schliesst er andererseits auch: was subjektiver Natur ist, ist von keiner Bedeutung für die Welt der Dinge an sich und verfällt damit einem Widerspruch. Denn jetzt sagt er: Raum und Zeit sind subjektiver Natur, sie haben somit keine Giltigkeit für die Welt der Dinge an sich. Dieser Schluss ist das gerade Gegenteil vom ersten; früher hat er aus lauter subjektiven Elementen auf ein Objekt (Ding an sich) geschlossen, jetzt erklärt er diesen Schluss, den er früher selbst gemacht hat, für unzulässig. Lassen wir aber letzteren Schluss, den der transscendentalen Ästhetik, gelten, so ist der auf das Ding an sich unzulässig. Beide, die Raum- und Zeitlehre und das Ding an sich widersprechen einander somit, und es ist daher historisch sehr begreiflich, dass man Kants Lehre durch Eliminieren des Dingbegriffes einerseits (Fichte), durch Beseitigung der Lehre von der Idealität des Raumes andererseits (Herbart) konsequent $\mathrm{zu}$ machen versucht hat, was freilich nur unter gänzlicher Zertrümmerung derselben durchzuführen möglich gewesen wäre.

Die Ungereimtheit der Lehre von der Idealität des Raumes lässt sich auch leicht an allerlei „artigen“ Widersprüchen erkennen; z. B. aus der Erwägung, wie es komme, dass wir eine Kugel immer als Kugel und niemals als Würfel sehen? An dem Ding an sich kann es nicht liegen, denn das hat gar nichts mit räumlichen Verhältnissen zu thun, an dem Subjekt aber auch nicht, denn das ist in beiden Fällen dasselbe.

Dadurch, dass sich schon der Ausgangspunkt Kants als unhaltbar erweist und unvermeidlich $\mathrm{zu}$ unhaltbaren Konsequenzen führt, wird natürlich sein System als solches hinfällig. Es bleibt daher nur noch zu untersuchen übrig, ob wenigstens nicht Teile desselben eine .selbständige Bedeutung beanspruchen können, da ja eine etwaige Rekonstruktion des Ganzen sich wegen der funda- 
Kant und die naturwissenschaftliche Erkenntniskritik der Gegenwart.

mentalen Bedeutung der beanstandeten Elemente als unmöglich erweist.

Es wird nicht überflüssig sein, vorerst noch bei der Kritik der transscendentalen Ästhetik zu verweilen, da ja dieselbe für das ganze System von vorbildlicher Bedeutung war. Kant hat ja für dieselbe Bewcise gegeben; was gilt von diesen? Nun das eigene Urteil Kants: schon ihre Zahl macht sie verdächtig! In der That, es sind nichts weniger als „Beweise“, was Kant unter diesem Namen ausgiebt. Es ist nichts weiter als eine total ungerechtfertigte Behauptung, zu sagen, die Vorstellungen des Raumes müssten schon zu Grunde liegen, damit gewisse Empfindungen auf etwas ausser mir bezogen werden. Ohne Gegenstände der Erscheinung ist ja ganz gewiss kein Raum möglich. Erst Gegenstände ausser mir erlauben das Legen eines Koordinatensystems und damit Raumbestimmungen. Eine fertige räumliche Anschauung ist gewiss nicht vorhanden, eine solche entwickelt sich ja erst mit der Zeit, der operierte Blindgeborne sieht zunächst alles in einer Ebene, der haptische Raum ist nicht identisch mit dem optischen und keiner derselben mit dem Raume des Geometers. Das alles ist doch zum mindesten Grund genug, dass man das Gegenteil dieser von der heutigen Psychologie und Physiologie entwickelten Anschauung nicht als selbstverständlich hinstellen darf, mag man sich sonst zu diesen Ansichten bekennen oder nicht. „Die Scheidung zwischen der "Idee" der räumlichen Ausdehnung und den Erregungen, die eine Empfindung zusammensetzen, die wir im Stande - und für die Zwecke des diskursiven Denkens gezwungen - sind, auszuführen, ist nicht eine in der Anschauung gelegene, sondern eine begriffliche. Wenn wir ein objektiv reelles Ding betrachten, so können wir kraft unseres Abstraktionsvermögens auf die Eigenschaft der räumlichen Ausdehnung bei völliger Ausserachtlassung seiner sinnlichen Qualitäten unsere Aufmerksamkeit richten; doch sobald wir es versuchen, uns seine Ausdehnung als wirklich vorzustellen - ein Gedankenbild der Ausdehnung zu bilden, oder sie als eine besondere Form der Anschauung vorzustellen - sind wir sofort gezwungen, sie mit einem Datum der Empfindung $\mathrm{zu}$ bekleiden oder zu vergesellschaften, das wir als eine zufällige Rückwirkung eines physikalischen Prozesses deuten. Anschauung (im Kantischen Sinne) ist ein wesentlicher Teil der Empfindung und erscheint als solche in den Sinnesäusserungen 
ebenso wie in deren gedanklichen Reproduktionen. " ") Wie Stallo weiter ausfïhrt, kann auch der Raum, wenn er „rein subjektiv und ganz im Geiste gelegen ist, ganz gewiss keinen Grund für einen Schritt abgeben, der aus dem Geiste herausführt". ${ }^{2}$ ) Wenn Kant sagt, dass der Raum eine „notwendige Vorstellung a priori sei, die allen äussern Anschauungen zu Grunde liegt", so dreht er sich hiebei im Zirkel, denn was sind „äussere Anschauungen"? Doch nur die, denen die Vorstellung des Raumes zu Grunde liegt. Allen unsern Empfindungen liegt aber die Vorstellung des Raumes nicht zu Grunde, d. h. nicht alle enthalten räumliche Beziehungen an sich. Kant hat ferner behauptet, dass der Raum deshalb kein Begriff sei, weil nicht mehrere Räume 'möglich sind. Diese Behauptung ist durch die Wissenschaft vom Raume überholt worden; wir wissen heute, dass mehrere Raumbegriffe gleich gut denkbar sind und dass übrigens der physiologische Raum mit dem geometrischen nicht übereinstimmt. Aber auch abgesehen hiervon, kann diese Forderung nach einem angebbaren Umfang des Begriffes nicht aufrecht erhalten werden; man denke nur an die Begriffe "Welt" oder "Gott" oder selbst an einen beliebigen Individualbegriff. Aber auch, dass Geometrie nur unter Zugrundelegung dieser Ansicht vom Raume als Wissenschaft möglich sei, ist eine übereilte Annahme; die Geometrie von heute erhebt gar nicht den Anspruch darauf, eine Wissenschaft a priori zu sein; hat Kant vor mehr als 100 Jahren diese Annahme als eine selbstverständliche gelten lassen können, so sähe. er sich heute gerade vor die Aufgabe gestellt, den apriorischen Charakter nachzuweisen. Das wäre heute diejenige Behauptung, die am dringendsten eines Beweises bedürfen würde.

Man kann übrigens sagen, dass der eigentliche fundamentale Irrtum der Kantischen Raum- und Zeitlehre metaphysisch-ontologischer Natur ist. Er steckt darin, dass sich Kant die Frage vorgelegt hat: Was ist Raum? bezw. Was ist Zeit? Darin liegt eine unberechtigte Substantivierung, Verselbständigung, Hypostasierung dieser Begriffe. Raum ist weder etwas Objektives (wie Newton wollte) noch etwas Subjektives (nach Kant), er ist überhaupt nicht „etwas“. Raum und Zeit sind lediglich Worte (man könnte sagen substantivierte Adjektiva), die auf gewisse Begriffsverhältnisse

1) Stallo, l. c. S. 243.

2) Ib. S. 244 . 
hinweisen, aber nicht Begriffe oder „Anschauungen“, denen etwas Greifbares, wie bei den gewöhnlichen Begriffen, selbst denen der geometrischen Körper, zu Grunde liegt. Es verhält sich damit, wie Stallo ausfïhrt: „Der Raum ist ein Begriff, ein Produkt der. Abstraktion. Alle Gegenstände unserer sinnlichen Erfahrung zeigen die Eigenschaft der Ausdehnung in Verbindung mit einer Zahl verschiedener und veränderlicher Qualitäten der Empfindung; und wenn wir nach und nach von diesen verschiedenen Empfindungen abstrahiert haben, kommen wir schliesslich zu der Abstraktion oder dem Begriff einer Form räumlicher Ausdehnung. Ich sage ausdrücklich Form der Ausdehnung, und nicht einfach Aus dehnung oder Raum, denn das erstere und nicht das letztere ist das summum genus der hier angeführten Abstraktionskette. Wenn das Wort ,Begriff‘ in dem Sinne gebraucht wird, in welchem es den Repräsentanten eines möglichen Gegenstandes der Anschauung vorstellt, ist eine räumlich ausgedehnte Form das letzte Resultat des Verfahrens, durch welches ein Gegenstand oder eine Erscheinung begriffen werden kann. Die Abstraktion oder der Begriff (jetzt das Wort in einem weiteren Sinue gebrauchend) Ausdehnung im allgemeinen oder Raum wird durch eine andere Reihe von Abstraktionen erreicht, von denen ich später etwas zu sagen haben werde. Die Unterlassung des Unterscheidens dieser Begriffe, die keinen Bezug auf Grenzen und Formen haben von den wahren summa genera der Klassifikation der sinnlichen Gegenstände ist eine der Quellen der Verwirrung, die überall die Theorie des transscendentalen Raumes erfuillt, wie wir gleich sehen werden."1)

Man kann die transscendentale Ästhetik betrachten von welcher Seite auch immer, man wird nie zu einem andern Schlusse kommen können als dem, dass sie in ihrer Gänze als verfehlt zu betrachten ist. Ja man muss zugeben, dass Hume eine wesentlich richtigere Auffassung der Sache hatte, indem er alle Gegenstände der menschlichen Vernunft in zwei Klassen teilte, die ,relations of ideas“ und die ,matters of fact". Nit Unrecht hält ihm jedenfalls Kant vor, dass er die Urteile der Mathematik als analytische (im Sinne Kants) angesehen hätte, er sagt nur, dass die Begriffe derselben im Subjekte ihren Sitz haben, und das sagt Kant auch. Die Sätze der Geometrie sind auch "relations of ideas“, welche

1) 1. c. S. 245 . 
„ideas" aber in Betracht kommen, ist zwar einerscits willkürlich, andererseits aber durch dic Ruicksicht auf die Wirklichkeit, die „matters of fact", bedingt. Letzteres sind hier die geometrischen Grundthatsachen. Eine wesentlich präzisere Auffassung wird ermöglicht durch die Einbeziehung des Begriffes der Gestaltqualitäten, wie dies Cornelius ${ }^{1}$ ) in treffender Weise ausführt. Die Möglichkeit der Geometrie ist dann, wie ich in einem frïheren Aufsatze ${ }^{2}$ ) im Anschluss an den Gedankengang der Mechanik von Hertz und als Konsequenz desselben dargestellt habe und wie neuerdings H. Poincaré in gleicher Weise dargethan hat, ${ }^{3}$ ) dadurch gegeben, dass sie Bilder (Begriffe) des Raumes konstruiert und deren Eigenschaften untersucht. Inwiefern diese Bilder der Wirklichkeit entsprechen, ist Sache der Erfahrung zu untersuchen.

Die Ansicht von der bloss subjektiven Bedentung der Raumund Zeitformen war für das Kantische System von folgenschwerster Bedeutung; sie hat ihm dadurch, dass er alles, was in der Zeit geschah, als bloss von subjektiver Bedeutung angesehen hatte, von vornherein das T'erständnis der einzigen Quelle unseres Wissens, der unmittelbaren Erfahring, verschlossen. Das hat sich, mehr noch als an ihm, an jenen, die in seine Fusstapfen zu treten meinten, bitter gerächt. $\left.{ }^{4}\right)$

Die Lehre von der nur subjektiven Bedeutung von Raum und Zeit ist daher sehr weit davon entfernt, als eine verdienstliche Leistung angesehen werden zu können.

1) Einleitung in die Philosophie, S. $245 \mathrm{ff}$.

2) Die Entwicklung des Raum- und Zeitbegriffes in der neueren Mathematik und Mechanik und seine Bedeutung für die Erkenntnistheorie. Arch. f. system. Philos. her. v. Natorp 4. Bd. S. 32 ff. 1897. Icl bemerke, dass es dort auf S. 38 statt Mach, Lotze heissen muss.

3) La science et l' hypothèse. Paris, E. Flammarion 1902. : Ich mache noch auf die in diesem Buche enthaltene ausführliche Analyse des. Urteils $7+5=12$ besonders aufmerksam.

4) Andererseits hat freilich die Lehre von der Idealität von Raum und Zeit Kant auch dazu gedient, sich in schwierigen Fällen leicht aus der Verlegenheit zu ziehen. So ernst es auch Kant mit seinen diesbezüglichen Unternehmungen war, erwecken dieselben doch beim unbeteiligten Zuschauer den Eindruck von Taschenspielerkunststücken. Dahin gehört z. B. seine Lehre von der gleichzeitigen Kausalität und Freiheit menschlicher Willenshandlungen. Da sich letztere auf die unerkennbaren Dinge bezieht und dieselben in der eigentlichen Wissenschaft keine Rolle spielen dürfen, müsste man eigentlich Kant als Deterministen ansprechen - so paradox dies wieder von einem andern Gesichtspunkte aus erscheint. 
Sehr verbreitet ist die Ansicht,. dass die transscendentale Analytik Kants Hauptleistung auf dem Gebiete der theoretischen Philosophie vorstellt. Wie verhält es sich nun mit dieser?

In rein formeller Beziehung begegnen wir einer ganzen Schar von Mängeln. Mehr noch als früher die Mathematik tritt hier die Logik - und was für eine Logik! - mit dem Anspruch auf unbedingte axiomatische Giltigkeit ihrer Lehren auf. In Wirklichkeit müsste es natürlich umgekehrt die Erkenntnistheorie sein, die der formalen Logik ihre Stelle anweist und deren Grundsätze deduziert. Es war der Irrtum Kants, die Logik als über dem Strit der Parteien stehend und als etwas im wesentlichen Abgeschiossenes anzusehen. Von der Anerkennung dieses Standpunktes sind wir heute entfernter denn je. Wer kann z. B. sagen, was ein Begriff ist? ${ }^{1}$ ) Wir wissen bestenfalls, was er nicht ist. Machs Bemerkung über das Wesen des Begriffes, die denselbən als auf einer Thätigkeit, einer Reaktion des Organismus beruhend auffasst, ${ }^{2}$ ) und Rickerts ähnlich lautende Erklärungen in seiner Abhandlung "Zur Theorie der naturwissenschaftlichen Begriffsbildung." 3) sind fast das einzig Aufklärende dieser Art. Es ist daher natürlich, dass die sogenannte metaphysische Deduktion der Kategorien nicht als stichhaltig erkannt werden kann; ja es ist vieleicht denkbar, dass ein leiser Zweifel hieran Kant selbst aufgestigen ist und er daher die Aufschrift "Von dem Leitfaden ier Entdeckung etc." gewählt hat. Die Form der. Herleitung sit also gewiss hinfällig; was das Eegebnis derselben betrifft, so sind, wie schon Schopenhauer und nach ihm Paulsen hervorgeloben, viele, wenn auch nicht alle der aufgezählten Kategorien ielanglos, während andere wichtige Funktionen des Verstandes tehlen. Ich verweise da nur auf die Darstellungen englischer Ligiker (Sir William Hamilton, Bain, Jevons) auf Machs Prinzip cer Vergleichung und Denkanpassung, auf Volkmanns Prinzip der Isolation und Superposition. ${ }^{4}$ ) Man kann sagen, dass

1) Diese Frage hat sich Kant gar nicht gestellt - sehr zum Nachteil sines Systems. In Bezug auf den Gebrauch des Wortes Begriff verfährt ər mit unglaublicher Leichtfertigkeit.

2) Pop. wiss. Vorl., 3. Aufl., S. 278.

3) Vierteljahrschr. f. wiss. Philos. 1894, S. $277 \mathrm{ff}$.

4) Vgl. Volkmann, .Erkenntnistheoretische Grundzüge der Naturwisseschaften", Leipzig 1896, und „Einführung in das Studium der theoretisaen Physik", eb. 1900. 
die wichtigsten begriffsbildenden Funktionen in der Kantischen Kategorientafel fehlen.-

Die transscendentale Deduktion der Kategorien hat numentlich in der ihr in der zweiten Auflage zuteil gewordenen Fassung ') den grossen Vorteil, dass sie die Grundidee der gauzen Aroumentation, das ist die eigentliche Funktion der Kategorien klar hervortreten lässt, wenn sie auch freilich eine Ableitung der Kategorientafel nicht giebt. Für die Kritik ist das von Vorteil, usofern sich hieran die Prüfung des Grundgedankens, unabhängig von der speziellen Ausfïhrung anfügen lässt. Kant erklärt hier die. Kategorien als die Thätigkeiten des Verstandes, durch die erst der Begriff des Gegenstandes (der Erscheinung) und damit Effahrung zil stande komme. Wenn das richtig ist, so ist in der that der Verstand der Gesetzgeber der Natur und es giebt ein Wissen a priori als eine notwendige Bedingung jeder Erkenntnis. Dieser Gedanke erscheint an und für sich plausibel; und es ist auch ganz gewiss Kants besonderes Verdienst, den Anteil der spontanen Thätigkeit des Geistes an der Form alles Wissens mit Nachdruck betont zu haben. Das zu bestreiten liegt auch der empiristischen Schule der Erkenntniskritik fern, aber daraus allein ergifbt sich allerdings noch nicht die Richtigkeit der Deduktionen Kant. Sein Schluss ging dahin, dass erst die Thätigkeit des Verstandes den Begriff des Gegenstandes schaffe und dass daher der Bepriff des Gegenstandes seiner Form nach ein von vornherein festsehender sein müsse; daraus sollte dann weiter folgen, dass Erfahung nur unter gew̦issen apriorischen Bestimmungen möglich se. Von dieser Schlusskette ist nun bloss die erste Hälfte ricltig; der Begriff des Gegenstandes der Erscheinung ist allerding ein von unserem Geiste konstruierter und muss somit den Denggesetzen desselben folgen. Das ist von empiristisch-kritizistischer peite niemals bezweifelt worden; H. Hertz betont es mit grossem Nachdruck. ${ }^{2}$ Anders steht es aber um die Richtigkeit des zyeiten

1) Die von so vielen, auch Paulsen, in derselben gefundene Sc.ivenkung gegen den Realismus kann ich hingegen in derselben nicht füden; man sehe nur die Fussnote zu $\S 27$ ein, die eigens zur Zerstreuung derartiger Bedenken eingefügt wurde.

2) Einleitung in die Mechanik, Hertz' Werke III. Bd., S. 3: , Ganz werden sich leere Beziehungen nicht vermeiden lassen, denn sie kolmen den Bildern schon deshalb $z u$, weil es eben nur Bilder und zwar hilder unseres besonderen Geistes sind und also von den Eigenschaften finer 
Kant und die naturwissenschaftliche Erkenntniskritik der Gegenwart. 281

Teils der Schlussfolgerung. Von vornherein lässt sich schon einwenden; dass der Begriff des Gegenstandes zur Erfahrung gar nicht unentbehrlich ist. Kant, der eben das Wort "Erfahrung“" in einem ganz speziellen Sinne nimmt, kann das von seinem Standpunkte aus freilich nicht erkennen. Die Sache verhält sich aber so: Wenn ich z. B. sage, ich sehe einen Menschen oder ein Haus, so ist das - vom Standpunkte der strengen Wissenschaft, der ja hier allein in Betracht kommen kann - keine Thatsache der Erfahrung, sondern eine blosse Theorie, eine Hypothese. Der Leser findet eine ausführliche Analyse dieses Thatbestandes in Cliffords geistvollem Vortrag vor der Royal Institution (1873): "The philosophy of the pure sciences". 1) Hingegen ist es eine Thatsache der Erfahrung, wenn ich konstatiere: ich sehe weiss oder ich fuihle heiss. Die moderne Physik führt nun ihre Behauptungen durchaus auf solche Urteile letziterer Art zurück - wo sie dies etwa nicht thut, macht sie nur auf hypothetische (d. h. problematische) Giltigkeit Anspruch. In diesem Sinne wird also das Wort Erfahrung auf naturwissenschaftlicher Seite ganz allgemein verstanden, auf philosophischer scheint man sich fast durchgehends der Terminologie Kants anzuschliessen. ${ }^{2}$ ) Ist daher Kants Schluss schon aus diesem Grunde formal unzulässig, so ist er aus einer zweiten naheliegenden Bemerkung völlig belanglos; Kant erweist das Apriori als notwendige Bedingung der Möglichkeit der Erfahrung; nehmen wir an, der Náchweis sei ihm vollständig gelungen (was er nach dem vorhergehenden gar nicht ist), was beweist er? Gar nichts! Es fehlt der Nachweis, dass Erfahrung im Sinne Kants wirklich ist; das war es ja eben, was Hume bezweifelt hatte, und an diesem Nachweis ging Kant mit kaum glaublicher aber thatsächlicher Blindheit ganz vorbei - wohl eine seiner grössten Schwächen, die der Hinweis auf den damaligen Stand der Nathematik und mathematischen Naturwissenschaft nur sehr notdürftig entschuldigt. Kant hat sich hier verblïffen lassen. Noch auffallender ist es natürlich, dass so viele Interpreten Kants diese

Abbildungsweise mitbestimmt sein müssen“. S. 28: „Dell Bildern, welche wir uns von der Natur machen, können wir als unseren eigenen Schöpfungen Vorschriften machen".

1) Lectures and essays by the late W. K. Clifford, ed. by L. Stephen and Sir Fred. Pollock, 3. Aufl., London Macmillan 1901, I. Bd. S. $301 \mathrm{ff.}$

2) Vgl. hierüber meine Notiz: „Über den Begriff der Erfahrung", Arch. f. system. Philos. V. Bd., 3. H., S. 365, 1899. 
offene Lüicke nicht gesehen haben. ${ }^{1)}$ Sie ist jedoch, wie Vaihinger mit vollem Rechte nachdrücklich hervorhebt, schon zu Lebzeiten Kants von einem seiner Zeitgenossen, mit dem er in Briefwechsel gestanden, bemerkt und Kant vorgehalten worden, ${ }^{2}$ ) wie aus dem Briefe Ulrichs an Kant vom 21. April 1785 ersichtlich ist. Die Stelle lautet: „Gesetzt, der Gegner räumt mir ein: Nach dem Begriffe der Erfahrung, den Sie sowohl in der Kritik der reinen Vernunft als noch mehr in den Prolegomenen festgesetzt haben, sind die Kategorien zum Exempel die der Ursache und der Grundsatz der ursächlichen Verbindung die Bedingung selbst der Nöglichkeit solchartiger Erfahrung; er lengnet mir aber, dass der Mensch auf Erfahrung in der Bedeutung Berechtigung und Anspruch machen dürfe, wie soll ich ihm da kurz und gründlich begegnen?" Ganz ebenso trifft Paulsen den Kernpunkt der Sache mit der Bemerkung auf S. 208 seines Kantbuches: „Kants Denken zeigt an diesem Punkt eine fatale Neigung, sich im Kreise zu drehen. Was Hume bezweifelte, war die strenge (nicht die präsumtive) Allgemeinheit oder Notwendigkeit von Urteilen über Thatsachen überhaupt, also auch der Sätze der Physik und der angewandten Mathematik. Kant will sie ihm gegenüber beweisen, setzt sie aber im Grunde immer wieder voraus: im Begriff der Wissenschaft als solcher liegt nach ihm als wesentliches Merkmal der apodiktische Charakter, die Allgemeinheit und Notwendigkeit; wer ihren Sätzen diese bestreitet, der behauptet, dass es keine eigentliche Wissenschaft geben kann, der ist Skeptiker. Der Skeptizismus aber wird durch das Dasein der Wissenschaften, d. h. der mathematischen Naturwissenschaft widerlegt. ... Und dann garantieren umgekehrt wieder die apriorischen Grundsätze die Allgemeinheit und Notwendigkeit der Wissenschaften." Eben dahin zielt schliesslich auch die von Paulsen sehr mit Recht erhobene Frage nach der Möglichkeit synthetischer Urteile a posteriori (S. 147), deren Beautwortung „den ganzen Aufbau der Kritik zersprengt hätte“. Auch der bildliche Ausdrúck vom „Vorübergleiten des Kantischen Denkens" ist sehr glücklich gewählt. Kant hat gewiss garnicht daran gedacht, dass durch seine eigene Theorie die Möglichkeit von Erfahrungsurteilen zu nichte gemacht worden ist. Man kann so sagen, dass Kant selbst durch die ohne weiteres

1) $\mathrm{Zu}$ diesen zählen z. B. ausser K. Fischer auch Al. Riëhl und Windelband.

2) Kantstudien, Bd. V, 1891, S. 106. 
Bedenken anerkannte Möglichkeit synthetischer Urteile a posteriori stillschweigend die Unmöglichkeit solcher a priori eingesehen habe, wie man aus den Auseinandersetzungen Paulsens auf S. 182 seines Kantbuches ersehen kann: „Damit bricht die ganze Beweisführung mitten entzwei. Sie ruht auf der Voraussetzung, womit $\S 15$ anhob: , alle Verbindung, es mag eine Verbindung des Mannigfaltigen der Anschaunng oder der Begriffe, und an der ersteren der sinnlichen oder der nicht sinnlichen Anschauung sein, ist eine Verstandeshandlung". ,Verbindung liegt nicht in den Gegenständen und kann von ihnen nicht durch Wahrnehmung entlehnt werden, sondern ist allein eine Verrichtung des Verstandes'. Woher nun auf einmal ,empirisch bestimmte ${ }^{6}$ Erscheinungen, deren Gesetzmässigkeit kennen zu lernen ,Erfahrung: hinzukommen muss? Können aus ,Erfahrung“ Gesetze entnommen werden, deren Quelle nicht der Verstand ist? Dann gäbe es also Verbindungen der Erscheinungen nach Regeln, die aus der Rezeptivität der Sinnlichkeit stammen. Ist aber das der Fall, kann Verbindung überhaupt aus der Sinnlichkeit kommen, kann das Gesetz der Gravitation aus der ,Erfahrung، und nur aus der Erfahrung erkannt werden, warum dann nicht auch das Gesetz der Kausalität? In der That, hier stehen zu bleiben, ist unmöglich. Man muss entweder weiter gehen zum reinen Rationalismus, der die ganze Physik für logisch konstruierbar und demonstrierbar hält, wie Spinoza, oder die Natur selbst a priori deduziert wie Hegel, oder man muss den Empirismus rein durchführen, wie es, der Intention nach, D. Hume thut: alle Naturgesetze, alle Wahrheiten vọn Thatsachen (im Unterschied von mathematischen), auch die allgemeinsten, sind empirische Gesetze, freilich, so werden wir hinzufügen, nicht in dem Sinne, dass die Natur draussen sie den Sinnen imprimiert, wohl aber in dem Sinne, dass der Verstand sie im Hinblick auf die in der Wahrnehmung gegebenen Zusammenhänge in Raum und Zeit ausbildet und ihre Wahrheit an ihnen kontrolliert." Ich habe diese Stelle deshalb hier ganz ausführlich angeführt, weil sie mit Haaresschärfe den Standpunkt der Erkemntnistheorie von Mach, H. Hertz, Clifford, Stallo, Cornelius, L. Lange, kurz den des kritischen Empirismus - nach einem Ausdruck von Cornelius - wiedergiebt und diese Übereinstimmung umso auffallender ist, als sie bishcr fast die einzige Anerkennung des Machschen Standpunktes von rein philosophischer Seite her bedeutet. Gerade der fettgedruckte Schlusssatz entspricht, was ich besonders 
hervorheben möchte, ebenfalls aufs genaueste dem Standpunkt Nachs und berïhrt sich selbst in Wortlaut nahe mit einer Äusserung desselben in einem Briefe an Poske, die dieser bei Gelegenheit einer Besprechumg meines Aufsatzes „Über Ernst Machs und Heinrich Hertz' prinzipielle Auffassung der Physik" in der "Zeitschrift für den chemisch-physikalischen Unterricht" reproduziert hat. Schliesslich möchte ich noch erwähnen, dass ich dieselbe Anschauung bereits zu wiederholten Malen, das erstemal 1897 in meinem Aufsatz über den Raum- und Zeitbegriff im Archiv für systematische Philosophie und insbesondere auch in dem eben genannten über NIach und Hertz vertreten habe. Im ersteren heisst es z. B.: $\left.{ }^{1}\right)$ „Im Gegenteil sehen wir uns genötigt, an die Spitze unserer Systeme rein willkürliche Voraussetzungen zu setzen, dieselben in ihren Konsequenzen zu entwickeln und der Erfahrung das entscheidende Wort ïber ihre Richtigkeit oder wenigstens Zulässigkeit zu ïberlassen“. Die Worte „rein willkürlich" sind vielfach beanstandet worden und sind wohl auch nicht ganz zutreffend gewählt, indem ich mich von der Absicht, den subjektiven Charakter unserer Begriffswelt zu' betonen, etwas zu weit hinreissen liess; in Bezug auf sie oder einen ähnlichen Ausspruch hat sich dann Mach ganz ähnlich wie Paulsen - - dahin geäussert, dass unser Verstand die Begriffe in Hinblick auf die in der Erfahrung gegebenen $\mathrm{Zl}-$ sammenhänge schafft. In dem zweiten der oben genannten Aufsätze hob ich gleichfalls mit gesperrten Lettern hervor: $\left.{ }^{2}\right)$ „D er Ausgleich zwischen Rationalismus und Empirismus erfolgt also derart, dass ersterem vollständig die Konstruktion der Begriffe, letzterem ebenso uneingeschränkt dị Entscheidung über ihre Richtigkeit anheimfällt. Die konstruktive Thätigkeit des Denkens ist zur Entstehung eines natúrwissenschaftlichen Systemes.daher zwar notwendig aber nicht hinreichend".

Die mathematische Physik ist also wie die Geometrie ${ }^{3}$ ) eine

1) Arch. f. system. Philos. 4. Bd., S. 42, 1897.

2) Arch. f. system. Philos. 5. Bd., S. 180 f.; 1899.

3) Vgl. über dieselbe die bereits citierten Ausführungen von Poincaré, damn auch die von Felix Klein (Vorlesungen über die nicht-euklidische Geometrie, u. a.) und H. Grassniann, Ausdehnungslehre vom Jahre 1844. Clifford sagt kurz: "Geometry is a physical science", The common sense of the exact sciences, 4. Aufl., London, 1898, S. 47. 
Wissenschaft, bei der die formale Richtigkeit eine notwendige, aber keine hinreichende Bedingung bildet.

Mit dieser Fixierung des eigentlich wesentlichen Unterschiedes zwischen Kantischem und empirischem Kritizismus könnte eigentlich die negative Seite der Beurteilung des Kantischen Systems enden und sich die Betrachtung seiner positiven Bedeutung für die Gegenwart anschliessen, wenn K̇ant sich nicht noch bemüssigt gesehen hätte, an die Analytik der Begriffe eine solche der Urteile ànzugliedern. Wie Paulsen mit Recht konstatiert, gewinnt dadurch die Darstellung Kants gar nicht; das eigentlich Gezwungene und Überflüssige sind aber nicht die Urteile, sondern die Begriffe, deren Sinn eigentlich erst hier klar hervortritt. Denn die Begriffe, die Kategorien, bedeuten ja Thätigkeiten des Geistes; es wäre also naturgemäss, diese Thätigkeiten auch als solche gleich zu behandeln und sie nicht in die tote Form starrer Begriffe einzuzwängen. Die Kategorien sind gar nicht Begriffe im gewöhnlichen Sinne, sondern jene Funktionen des Geistes, welche erst Begriffe hervorbringen. Es ist daher auch die Darstellung der Grundsätze klarer und daher empfiehlt es sich, an ihnen das bisher Gesagte noch zu verdeutlichen.

-Vor allem verlohnt sich ein Blick auf die Kausalitätstheorie, weil dieselbe einerseits von so vielen Seiten als besonderer Glanzpunkt des Systems gepriesen worden ist, und andererseits doch gesagt werden muss, dass die Schwäche der Kantischen Beweisführung nirgends mit so durchsichtiger Klarheit hervortritt wie gerade hier. Gegenüber weit verbreiteten Ansichten muss ich erklären, dass ich in derselben durchaus keinen Fortschritt, sondern nur einen Rückschritt gegenüber der Ansicht Humes erblicken kann. Machs Anspruch „Die Humesche Kritik bleibt aufrecht" 1 ) pflichte ich vollkommen bei, wogegen ich dem von Natorp, ${ }^{2}$ ) wonach "die Frage der Kausalität seit 1781 anders liege," durchaus widersprechen muss. Denn Kant nimmt gerade das als selbstverständliche Annahme hin, was Hume eben bestritten hatte und beweist etwas, was Hume gar nicht bestritten hat, er verfällt somit seinem eigenen Vorwurf, den er den Nachfolgern Humes gegenüber gemacht bat. Ich bemerke dabei - um etwaigen Missverständnissen zu begegnen - dass ich Humes Auseinandersetzungen nicht in allem

1) Wärmelehre, 1. Aufl., S. 431.

2) Zur Streitfrage zwischen Empirismus und Kritizismus, Arch. f. system. Philos. 5. Bd. S. 195, 1899. 
beipflichten kann. Ich kann ihm, wie ich schon einmal hervorgehoben, ${ }^{1}$ ) den Vorwurf metaphysischer Denkungsart nicht ersparen. Er giebt zu, dass wir Kausalitiit nicht erkennen können und doch zweifelt er nicht an der Giltigkeit dieses Begriffes. Das widerspricht dem Prinzip der Exaktheit oder wie man auch sagen kann, dem der Voraussetzungslosigkeit des Denkens. Für übel angebracht halte ich alch sein Hereinbringen der Assoziationstheorie. Nur nach der negativen Seite seiner Kritik stimme ich ihm vollkommen bei. Um sie zu widerlegen, hätte Kant den Beweis für die apriorische Giltigkeit wenigstens einiger Kausalurteile zu erbringen gehabt. Fr hätte zeigen müssen, worin sich die Kausalurteile der Wissenschaft von den Kausalurteilen des Aberglaubens unterscheiden und das hat er nirgends geleistet. Da die letzteren offenbar unzulässig sind, müssen es auch die ersteren sein, denn es ist kein Grund ersichtlich gemacht worden, durch den man beide Arten von Kausalurteilen unterscheiden könnte. Man mag die Darstellung Kants in der Kritik oder in den Prolegomenen zur Hand nehmen, man wird sich fast bei jeder Zeile zu schärfstem Widerspruch herausgefordert fühlen. In der Kritik heisst der Grundsatz der zweiten Analogie: "Alle Veränderungen geschehen nach dem Gesetze der Verknŭpfung der Ursache und Wirkung". Ja, ist denn das wahr? Ist der Wechsel von Tag und Nacht nicht auch eine Veränderung und geschieht es etwa '„nach dem Gesetze der Verknüpfung der Ursache und Wirkung"? Bei manchen Veränderungen denken wir nachträglich die Begriffe von Ursache und Wirkung hinzu, niemals ist aber das Hineindenken dieser Begriffe Bedingung der Möglichkeit einer Erfahrung. Es ist eine vollständige Verkehrung der Sachlage, wenn es ein paar Seiten später heisst: „Ich werde also in unserem Falle die subjektive Folge der Apprehension von der objektiven Folge der Erscheinungen ableiten müssen, weil jene sonst gänzlich unbestimmt ist und keine Erscheinung von der anderen unterscheidet". „Gänzlich bestimmt" ist die subjektive Folge, sie ist ja doch ein Gegenstand der unmittelbaren Wahrnehmung. Das, was Kant objektive Folge nennt, ist eine blosse Theorie, über die ich nach Massgabe verschiedener. subjektiver Folgen urteilen. werde. Es ist wieder der Dualismus bezw. der

.) J. B. Stallo als Erkenntniskritiker, Vierteljschr. f. wiss. Philos. 25. Bd. S. 411, 1901. 
Kant und die naturwissenschaftliche Ërkenntniskritik der Gegenwwàrt. 287.

Realismus Kants, der sich hier in verderblichster Weise geltend macht. Auch hier setzt Kant dem Begriffe des Subjektes, den des Objektes (zwar nicht im Sinne eines Dinges an sich, sondern in dem eines Gegenstandes der Erscheinung) in schroffer, ganz unhaltbarer Weise entgegen und verschliesst sich infolgedessen der Erkenntnis der einzigen Quelle unseres Wissens: der unmittelbaren Erfahrung. Das scheint mir wenigstens noch der plausibelste Erklärungsgrund für die Möglichkeit einer zu so handgreiflich falschen Konsequenzen führenden Denkweise zu sein. In den Prolegomenen tritt dieselbe noch drastischer hervor, denn hier tritt die ganze Leere der Deduktion an dem von Kant selbst gewählten Beispiele augenscheinlich zu Tage. Mit welchem Rechte kann ich auf Grund des Urteils „Wenn die Sonne den Stein bescheint, so wird er warm" das Urteil bilden „Die Sonne erwärmt den Stein“? Enthält das zweite Urteil mehr wie das erste - wie Kant behauptet -, welches Recht haben wir dann es aufzustellen? Wenn dann Kant sagt, in diesem Falle „komme über die Wahrnehmung noch der Verstandesbegriff der Ursache hinzu, der mit dem Begriff des Sonnenscheins den der Wärme notwendig verknüpft, und das synthetische Urteil wird notwendig allgemeingiltig, folglich objektiv und aus einer Wahrnehmung in Erfahrung verwandelt", so beschreibt er hier den Vorgang des vulgären unwissenschaftlichen Denkens, denselben, dessen Berechtigung Hume eben bestritten hatte. Es ist ganz merkwürdig, wie Kant an der Frage nach dem Rechte dieses Hinzudenkens des Verstandesbegriffes so schlankweg vorbeigehen konnte, nachdem dieselbe doch von Hume so nachdrücklich als solche formuliert worden war.

Noch merkwürdiger ist natürlich, dass seine Interpreten diesen fundamentalen Mangel nicht bemerkt oder ihn gar noch überboten haben. Wenn z. B. Kuno Fischer geradezu erklärt: ${ }^{1}$ ) „Die Zeit als solche ist völlig subjektiv, sie ist die Form unserer Anschauung, unserer Vorstellungsweise; in ihr verlaufen unsere Wahrnehmungen mit ihren Erscheinungen. Da ist zunächst kein Grund, warum diese Erscheinung nicht eben so gut jetzt als früher oder später stattfindet. Die Frage heisst: was verknüpft diese bestimmte Erscheinung mit diesem bestimmten Zeitpunkt? Der Zeitpunkt ist nicht reguliert, weder durch die Zeit, die alle Erscheinungen in sich begreift, noch durch

1) In der 3. Auflage seines Kantwerkes auf S. 394. 
die Erscheinung, die in jedem beliebigen Zeitpunkte sein kann," - so ist denn das doch zu stark. Eine solche unsinnige „Völligkeit der Subjektivität“, nach der es ganz beliebig sein sollte, wann wir den Zeitpunkt einer Erscheinung einordnen - weil die Zeit eben etwas völlig Subjektives ist ${ }^{1}$ ) - diurfte wohl nicht einmal im Sinne Kants gewesen sein. Was ihn irregeführt, war wohl nur die Verkennung der Bedeutung der unmittelbaren Erfahrung, sein realistisches Vorurteil, das in der subjektiven Wabrnelımung nur etwas Minderwertiges erblickt hatte und erst die in seiner Weise bestimmte "objektive Erfahrung" als Erfahrung gelten liess. An die Möglichkeit, dass diese "objektive Erfahrung" (im Sinne Kants) durch eine subjektive geprüft werden könne, hat Kant offenbar gar nicht gedacht. Das ist aber eine Sache, die jedem Naturforscher von vornherein ganz klar ist; denn die Sätze der Naturwissenschaft enthalten doch auch Prophezeiungen für die Zukunft und somit muss es möglich sein, ihre Richtigkeit durch einfache Wahrnehmungsurteile, wie "es ist hell", "es ist dunkel" zu prüfen. ${ }^{2}$ )

Nicht weniger klar und durchsichtig ist der Irrtum Kants in der ersten Analogie beim Grundsatz von der Beharrlichkeit der Substanz. Auch diese ist durchaus keine notwendige Bedingung einer Erfahrung; um den Wechsel, die Veränderung konstatieren zu können, bedarf es einer absolut unveränderlichen Substanz keineswegs. So kann man die Bewegung zweier Körper konstatieren, wenn auch keiner derselben in Ruhe ist, ja es hat sogar letzterer Ausdruck keimen wissenschaftlich angebbaren Sinn. Ein relativ Bestïndiges muss überall als Vergleichskörper schon deshalb ausreichen, weil es ein absolut Beständiges nicht giebt. Das ist einfach eine Thatsache der Erfahrung, gegen die es keine Berufung auf eine höhere Instanz giebt. Es ist dies namentlich von Mach,

1) Der Fehler liegt darin, dass subjektiv = willkürlich gesetzt wird. Das ist unberechtigt.

2) Vgl. den Schluss meiner Ausführungen über den Raum- und Zeitbegriff im Arch. f. system. Philos. 4. Bd., S. 42 f. Es ist dort darauf hingewiesen, dass eine theoretische Vorausberechnung irgend einer physikalischen Konstante durch ein einfaches Wahrnehmungsurteil geprüft, $d . h$. bestätigt oder widerlegt werden kann.

Kurz und treffend fasst $K$. Pearson (The grammar of science, 2 ed., London 1901), ein Mach nahestehender Denker, das Urteil über den Kausalbegriff in den Worten zusammen: „Necessity belongs to the world of conceptions, not to that of perceptions". 
Kant und die naturwissenschaftliche Erkenntniskritik der Ġegenwart. $28 \overline{9}$

Stallo ${ }^{1}$ ) und Paulsen ${ }^{2}$ ) so klar und ausführlich auseinandergesetzt worden, dass es genügen kann, sich auf deren Ausführungen zu berufen. Bemerkt mag nur werden, dass demjenigen, der dieses Faktum leugnen möchte, ein sehr einfaches Mittel der Widerlegung zu Gebote steht: er gebe einfach eine solche unveränderliche Sub$\operatorname{stanz}$ an!

Viel glücklicher war Kant in der Aufstellung der Antizipationen der Wahrnehmung. Kann man auch seine Deduktion nicht als einen Beweis a priori für die durchgängige Stetigkeit der intensiven Grössen gelten lassen, so ist doch seine Betonung der Wichtigkeit dieses-Begriffes der Intensivität gegenüber den Versuchen der mechanischen Physik, mit dem blossen Begriffe rein extensiver Grössen sein Auskommen zu finden, sehr am Platze. In diesem Punkte hat Kant im Sinne der heutigen phänomenalistischen und energetischen Auffassung der Physik gedacht.

Die Axiome der Anschauung enthalten die Deduktion der Grundsätze der angewandten Mathematik. Da Kant selbst zugiebt, dass zur Bildung der geometrischen Begriffe wie der einer Linie es einer Verstandesthätigkeit bedarf, so ist dieser Ort für diese Frage auch der angemessene. Allein das Resultat kann auch in diesem Falle nicht als ein zulässiges angesehen werden, die Sätze der Geometrie gelten nur von den Idealbegriffen derselben, jede Anwendung dieser Sätze ist empirischer Natur und enthält eine Berufung auf die Erfahrung. Kants Schluss „Die empirische Anschauung ist nur durch die reine möglich, was also die Geometrie von dieser sagt, gilt auch ohne Widerrede von jener" ist unrichtig, weil es der Obersatz ist; gegeben ist uns nur die empirische Anschauung, während die reine eine blosse Abstraktion aus derselben ist. Kant verfährt natürlich konsequent seiner Grundanschauung gemäss, aber diese ist eben unzulässig.

Bezüglich der Dialektik mag hier die Bemerkung genügen, dass von einem wirklichen transscendentalen Schein im Sinne

1) Stallo betont insbesondere mit grossem Nachdruck das Prinzip der Relativität, in dessen Verkündigung man nie $\mathrm{zu}$ überschwänglich sein könne. Vgl. dessen „Begriffe und Theorien der modernen Physik" S. $186 \mathrm{ff}$. Die Litteratur über die Relativität der Bewegung und die damit zusammenhängenden Fragen findet sich am vollständigsten bei L. Lange, „Das Inertialsystem vor dem Forum der Naturforsclung", Leipzig, Engelmann 1902 (Wundtfestschrift, XX. Bd. der "Philosophischen Studien").

2) Kantbuch, S. $191 \mathrm{ff}$. 
Kants nicht die Rede sein kann. Die "Ideen der Vernunft" sind von vornherein unberechtigte Begriffsbildungen, da es der Begriff des Absoluten (Unbedingten) ist; ${ }^{1}$ ) sie haben also auch nicht diejenige positive Bedeutung, die ihnen Kant noch lässt. Es handelt sich bei ihnen um wirkliche, blosse Scheinprobleme, die aus einer verkehrten Fragestellung entspringen. Im übrigen verweise ich auf die Auflösung der Antinomien bei H. Cornelius. ${ }^{2}$ )

Es eriibrigt nur noch, auf eine Grundvoraussetzung des Kantischen Denkens von allgemeinster Bedeutung hinzuweisen, die von der heutigen Wissenschaft nicht mehr geteilt wird. Der Titel deutet sie schon an, es ist die Voraussetzung von einer unfehlbaren, allen Menschen in gleicher Weise zukommenden Vernunft, das Wort im allgemeinsten Sinne genommen (einschliesslich der anderen Geisteskräfte des Menschen, wie es ja wohl auch im Titel der Kritiken gemeint ist). Diese rationalistische Voraussetzung gilt Kant von vornherein als so selbstverständlich, dass sie einer besonderen Prüfung auf ihre Berechtigung hin gar nicht bedarf. Am augenfälligsten tritt diese Grundvoraussetzung dort hervor, wo Kant die Möglichkeit eines Irrtums zu erklären unternimmt (am Anfange der Dialektik), der in der That von seinem Standpunkte aus ganz unmöglich wäre. Hier bezeichnet Kant ausdrücklich Sinne und Verstand als „Kräfte der Natur", von denen sogar physikalische Gesetze gelten sollen. Ich hebe diese Stelle gerade deshalb hervor, weil sie in unwiderleglicher Weise die subjektiv-psychologische Grundanschauung Kants darthut, und dieselbe von Seite so vieler Anhänger wegzudeuten oder gar als absurd hinzustellen versucht worden ist. Gewiss kommt bei Kant auch die objektive, transscendentale Methode zur Geltung, deren Begründer zu sein ja Kants eigenstes Verdienst ist und die sachlich ja auch weit wertvoller ist; das alles giebt aber doch noch kein Recht zu leugnen, dass die ursprünglichere, frühere und zum grossen Teile stehen gebliebene Ausicht Kants die subjektiv-psychologistische war, die er selbst als metaphysische bezeichnet. So basieren die metaphysischen Deduktionen der Ästhetik und die von Kant selbst (in der Vorrede zur ersten Auflage) als subjektiv. bezeichnete Deduktion der Kategorien auf derselben. In der zweiten Auflage ist allerdings letztere gestrichen worden, ein Zeichen für die Fort-

1) Siehe Stallo, 1. c., S. $186 \mathrm{ff}$.

2) Einleitung in die Philosophie, S. $331 \mathrm{ff}$. 
entwickelung des Kantischen Denkens von der psychologischen zur transscendentalen Methode. Das ursprüngliche Vorhandensein der ersteren erklärt sich auch leicht durch den Hinblick auf Locke. Allerdings besteht aber zwischen Locke und Kant in dieser Beziehung ein wesentlicher Unterschied, Locke denkt in der Psychologie empiristisch, Kant rationalistisch und zwar derart, dass er auf seine rationalistisch-psychologischen Begriffe und Entwicklungen das Wort Psychologie gar nicht zur Anwendung bringt. Der Begriff dieses Wortes ist eben bei Kant ein anderer als in der hentigen W'issenschaft. ${ }^{1}$ ) Daher kommt es auch, dass, wie Paulsen sehr richtig bemerkt, ${ }^{2}$ ) Kant an der rationalistischen Anschauung vom Wesen des Begriffes im Grunde immer festgehalten hat. "Analytische Urteile setzen voraus, dass Begriffe feste Wesenheiten sind, die der Verstand vorfindet und durch Analysis sich verdeutlicht. Das ist die Anschaunng, die der realistische Rationalismus durch alle Wandlungen festgehalten hat: wahre Begriffe haben als solche Realität, jedes denkbare Wesen hat wenigstens einen in ihm liegenden Anspruch auf Wirklichkeit, eine Art Halbwirklichkeit, das ist die ,innere Möglichkeit'. Die Erfüllung dieses Anspruchs ist die förmliche Wirklichkeit. Das ist der Satz Wolffs: Dasein ist Ergänzung der Möglichkeit (complementum possibilitatis), ein Satz, der auf Leibnizens Schöpfungstheorie zurückweist: alles Denkbare ist möglich, ein ens possibile; unter den unzähligen möglichen Dingen, die in Gottes Intellekt sind, wählt er aus und giebt förmliche Wirklichkeit denjenigen, die in ihrer Gesamtheit das Maximum kompossibler Realität oder Vollkommenheit darstellen; wohingegen bei Spinoza der Umfang der Möglichkeit und Wirklichkeit zusammenfallen, Realität ist ihm nichts als Cogitabilität, notwendiges Gesetztsein in der Begriffswelt. Kant hat sich von dieser rationalistischen Anschauung, von der er ausgegangen ist, in den sechziger Jahren loszulösen begounen, aber er hat sich niemals ganz von ihr gelöst. Die Begriffe sind ihm fertige Wesenheiten geblieben, die man auflösen, in ihre Bestandteile zerlegen kann: dann erhält man analytische Urteile, die a priori feststehen.

1) Dass Kant der Chemie und Psychologie den Namen einer Wissenschaft abspricht, entschuldigt sich einigermassen durch die Thatsache, dass zu seinen Lebzeiten noch keine dieser Wissenschaften bestanden hat. Freilich war diese Ableugnung eine Folge seiner rationalistischen Denkweise.

2) S. 143. 
Man kann ihnen aber auch Prädikate geben, die nicht aus den wesentlichen Merkmalen abgeleitet werden können: dann erhält man synthetische Urteile".1) Deshalb hat wohl auch Kant in der Kritik den Gang eingeschlagen, dass or zuerst die Begriffe aufstellt und hintennach erst ihre Berechtigung nachweist - ein doch an sich sehr sonderbares Verfahren. Eine zweite Konsequenz seiner rationalistischen Denkweise war die Übernahme des Platonischen Wissenschaftsbegriffes. Kant hat denselben allerdings dem Umfang c seiner Giltigkeit nach bedeutend restringiert, ist aber in der Idee nie von ihm abgewichen. Erst für die moderne Wissenschaftstheorie entstand durch die Zerstörung jeglichen Aprioris die Notwendigkeit, einen neuen Begriff der Wissenschaft aufzustellen.

\section{Die positive Bedeutung der Kantischen Erkenntnis- theorie für die moderne exakte Wissenschaft.}

Es könnte nach der im Vorhergehenden durchgeführten, zum grössten Teile ablehnènden Kritik den Anschein haben, als würde Kants Gedankenkreis für die Gegenwart, d. h. wenigstens für die exakte Wissenschaft von keiner Bedeutung mehr sein können. Das wäre indess eine zu voreilige Annahme. Seine Bedeutung ist eine doppelte; eine mehr historische als Bahnbrecher erkenntnistheoretischer Betrachtungsweise und eine positive im engern Sinne des Wortes.

Kants fundamentale historische Bedeutung auch nur anzuzweifeln, dürfte wohl niemand beifallen; wonach allerdings gefragt werden könnte, ist lediglich der Umstand, wieso es komme, dass trotz der vielen hervorgehobenen Mängel Kants Lehre eine solche Rolle habe spielen können, als ihr thatsächlich zugefallen ist. Man wird auch billigerweise fragen dürfen, warum es nicht schon Locke, Berkeley oder Hume, deren Lehren ja älter und z. T. in mancher wichtigen Beziehung auch richtiger sind, geglückt sei, sich eine ähnliche Position zu erringen.

1) Damit im Zusammenhang steht die-Auffassung der Noumena, d. h. der Dinge an sich als begrifflicher Wesenheiten und die Hypothese von einem göttlichen Verstande, der ohne Anschauung die Dinge (eben deshalb, weil sie an sich, wie bei Plato, begrifflicher Natur sind) zu erkennen vermöchte. Die rationalistische Denkweise bildet eben den Schlüssel zur Metaphysik Kants. 
Der Begründer der Erkenntnislehre, der Urheber des Gedankens, dass man zuvor die Natur des Verstandes untersuchen müsse, bevor man sich mit demselben auf das spekulative Gebiet herauswage, ist ja nicht Kant, sondern Locke. Er hat ja auch bereits die wichtigsten Daten gesammelt und sein Buch ist nicht weniger dick ausgefallen als die Vernunftkritik. Der Vorrang aber, den letztere bezüglich der Methode erhebt, hat sich in dieser Art nicht als berechtigt herausgestellt; man könnte sich also fragen, ob nicht das eigentliche Verdienst Locke gebühre. Gewiss ist dasselbe nicht zu unterschätzen, trotzdem hat aber Kant doch sehr wesentliche Vorzüge vor Locke voraus. Einmal ist letzterer trotz seines Empirismus noch immer mehr Metaphysiker als Kant, dann ist seine Darstellungsweise mehr populär als wissenschaftlich. Das gilt aber nicht nur von dem Stil, sondern auch von der Art der Gedankenfolge; Kants Arbeit ist ohne Zweifel viel gründlicher und gewissenhafter. Kant verarbeitet auch ein ungleich grösseres Material, dann geht er ein auf die Theorie der Erkenntnis in jenen Wissenschaften, die zu seiner Zeit vorzugsweise als solche gegolten haben. Das sind alles Vorzüge, durch die sich Kant auch von seinen andern Vorgängern unterscheidet, und die das Manco an Originalität, das er ihnen gegenüber aufweist, wieder wettmachen. Bei Hume kommen auch positive Mängel in Betracht, 'seine Associationspsychologie und die daraus sich ergebende Verkennung der Aktivität des Geistes, so dass Hume gegenüber Locke und Berkeley in vieler Hinsicht einen Rückschritt bedeutet. Des letzteren Erkenntnistheorie ist nun allerdings ohne Zweifel der Kantischen weit überlegen; ${ }^{1}$ ) merkwürdigerweise blieb ihr aber ein wesentlicher Einfluss, auf die Zeitgenossen versagt, vielleicht deshalb, weil ihr Urheber denselben allzu weit voraus war und seine in einer Art genialer Intuition erschauten Gedanken ebenso einfach und anspruchslos niederschrieb, als er sie gefunden hatte, während Kant, was er

1) Eine eingehende Begründung dieser Behauptung behalte ich mir für später vor. Richtig ist - wie ich auch an mir selbst gefunden habe -, dass der erste Eindruck der Lektüre der "Prinzipien“ der eines Paradoxen ist. Vielleicht empfiehlt sich zur Einführung besser der erste der Dialoge zivischen Hylas und Philonous, um deren deutsche Herausgabe sich R. Richter jedenfalls ein Verdienst erworben hat, wenn ich auch seinen doch noch immer herabsetzenden Bemerkungen über Berkeley nicht zustimmen kann. 
mühsam erarbeitet, ebenso umständlich auseinandersetzt. Schliesslich haben auch ïussere Umstände, wie das hohe Alter, das Kant erreichte, und der Umstand, dass er aus der herrschenden Schulphilosophie hervorgegangen war, dazu beigetragen, seiner Kritik der Erkenntnis die überwiegende Stellung zu verschaffen, die sie crhalten.

Auch für die Entwickelung der naturwissenschaftlichen Erkenntniskritik war Kant von grossem Einfluss. Nach führt den ersten Impuls zum Verlassen der bisher allgemein üblich gewesenen Anschauungsweise der Naturforscher wie des gemeinen Mannes und zur Bildung einer neuen Auffassungsweise des Weltbildes auf Kant zurïck. "Ich habe es stets als besonderes Glück empfunden, dass mir sehr früh (in einem Alter von 15 Jahren etwa) in der Bibliothek meines Vaters Kants ,Prolegomena zu einer jeden künftigen Netaphysik' in die Hand fielen. Diese Schrift hat damals einen gewaltigen unauslöschlichen Eindruck auf mich gemacht, den ich in gleicher Weise bei späterer philosophischer Lektüre nie mehr gefühlt habe. Etwa 2 oder 3 Jahre später empfand ich plötzlich die müssige Rolle, welche das "Ding an sich“ spielt. An einem heitern Sommertage im Freien erschien mir einmal die Welt samt meinem Ich als eine zusammenhängende Masse von Empfindungen, nur im Ich stärker zusammenhängend“. Weiter als auf eine erste Anregung erstreckt sich allerdings Kants Einfluss auf Mach schwerlich. Er nennt seinen Namen einigemale in seinen Werken. Die wichtigsten dieser Stellen sind etwa die folgenden: „Es war eine grosse ernüchternde Kulturbewegung, durch welche die Menschheit im 18. Jahrhundert zur vollen Besinnung kam. Sip schuf das leuchtende Vorbild eines menschenwïrdigen Daseins zur Überwindung der alten Barbarei auf praktischem Gebiete; sie schuf die Kritik der reinen Vernunft, welche die begrifflichen Truggestalten der alten Metaphysik ins Reich der Schatten verwies, sie drückte der physikalisch-mechanischen Naturansicht die Zügel in die Hand, die sie hente führt". ${ }^{1}$ " „Die fertige Erfahrung im Setzen der Gedankenmosaik, mit welcher wir jedem neuen Fall entgegenkommen, hat Kant einen angeborenen Verstandesbegriff genannt“. ${ }^{2}$ ) "Wir wollen uns nur er-

1) Die ökonomische Natur der physikalischen Forschung, Festvortrag 1882, enthalten in „Populär-wiss. Vorl.“; in der 3. Aufl. auf S. 216.

2) Ebd., S. 2:8. 
innern, dass Newton noch von einer absoluten, von allen Erscheinungen unabhängigen Zeit, wie auch von einem absoluten Raum spricht, über welche Anschauungen selbst Kant nicht hinausgekommen ist, und die heute noch zuweilen ernstlich erörtert werden." ${ }^{1}$ ) „Die verschiedene Kraft solcher Kausalitätsurteile treibt nun zur Untersuchung über die Natur derselben, und erzeugt eben das Hume-Kantsche Problem: Wie kann das Bestehen eines Dinges A überhaupt zur notwendigen Bedingung des Bestehens eines andern B werden? Beide Denker lösen dasselbe in ganz verschiedener Weise, und zwar Hume in der schon erwähnten, der wir beipflichten. Kant hingegen imponiert die thatsächliche Kraft, mit der Kausalitätsurteile auftreten. Ihm schwebt nachweislich als Ideal das Verhältnis von (Erkenntnis-) Grund und Folge vor. Der ,angeborene Verstandesbegriff' erscheint ihm sozusagen als Postulat, um das thatsächliche Bestehen der Kausalitätsurteile psychologisch zu verstehen. Dass es sich aber nicht um einen angeborenen, sondern um einen durch die Erfahrung selbst entwickelten Begriff handelt, lehrt die einfache Überlegung, dass der erfahrene Physiker sich einer nenen zum ersten Mal beobachteten Thatsache gegenüber doch ganz anders verhält, als das unerfahrene Kind derselben gegenuiber. Eine Erfahrungsthatsache wirkt eben nicht durch sich allein, sondern setzt sich mit allen vorausgegangenen in psychische Beziehung. So kann allerdings der Eindruck entstehen, als ob wir durch eine einzelne Thatsache etwas erfahren könnten, was nicht in ihr selbst liegt. Dieses Etwas, was wir hinzuthun, liegt eben in der Summe der vorausgegangenen Erfahrung." 2) Im allgemeinen kann man sagen, dass es die antimetaphysische Seite des Kantischen Denkens ist, die Mach anerkennend hervorhebt aber nicht als durchaus ausreichend erachtet. Übrigens finden sich auch sonst noch Berührungspunkte. So wie Kant hebt auch Mach die Aktivität des Denkens hervor. Er pflichtet dem Ausspruch Schopenhauers über „den Willen, der sich den Intellekt für seine Zwecke schuf", bei, ${ }^{3}$ ) und betont namentlich in seiner Auffassung des Begriffes die eigene Thätigkeit des Geistes. „Wir dürfen nicht denken, dass die Empfindung ein rein passiver Vorgang ist.

1) Ebd., S. 233.

2) Prinzipien der Wärmelehre, 1. Aưfl. 1896, S. $432 \mathrm{f}$.

3) Pop. wiss. Vorl., 3. Aufl., S. 219. 
Die niedersten Organismen antworten auf diesselbe mit einer einfachen Reflexbewegung, indem sie die herankommende Beute verschlingen. Bei höheren Organismen findet der centripetale Reiz im Nervensystem Hemmungen und Förderungen, welche den centrifugalen Prozess modifizieren. Bei noch höheren Organismen kann - bei Prüfung und Verfolgung der Beute - der berührte Prozess eine ganze Reihe von Zirkelbewegungen durchlaufen, bevor derselbe zu einem relativen Stillstand gelangt. Auch unser Leben spielt sich in analogen Prozessen ab, und alles, was wir Wissenschaft neunen, können wir als Teile, als Zwischenglieder solcher Prozesse ansehen. Es wird nun nicht mehr befremden, wenn ich sage: Die Definition eines Begriffes, und, falls sie geläufig ist, schon der Name des Begriffes, ist ein Impuls zu einer genau bestimmten, oft komplizierten, prüfenden, vergleichenden oder konstruierenden Thätigkeit, deren meist sinnliches Ergebnis ein Glied des Begriffsumfangs ist. Es kommt nicht darauf an, ob der Begriff nur die Aufmerksamkeit auf einen bestinmten Sinn (Gesicht) oder die Seite eines Sinnes (Farbe, Form) hinlenkt, oder eime umständliche Handlung auslöst, ferner auch nicht darauf, ob die Thätigkeit (chemische, anatomische, mathematische Operation) muskulär, oder gar technisch, oder endlich nur in der Phantasie ausgeführt, oder gar nur angedeutet wird. Der Begriff ist für den Naturforscher, was die Note für den Klavierspieler. Der geübte Mathematiker oder Physiker liest eine Abhandlung so, wie der Musiker eine Partitur liest. So wie aber der Klavierspieler seine Finger einzeln und kombiniert erst bewegen lernen muss, um dann der Note fast unbewusst Folge zu leisten, so muss auch der Physiker und Nathematiker eine lange Lehrzeit durchmachen, bevor er die mannigfachen feinen Innervationen seiner Muskeln und seiner Phantasie, wenn ich so sagen darf, beherrscht. Wie oft führt der Anfänger in Mathematik oder Physik anderes mehr oder weniger aus, als er soll, oder stellt sich anderes vor. Trifft er aber nach der nötigen Übung auf den ,Selbstinduktionskoeffizienten', so weiss er sofort, was das Wort von ihm will. Wohlgeübte Thätigkeiten, die sich aụs der Notwendigkeit der Vergleichung und Darstellung der Thatsachen durch einander ergeben haben, sind also der Kern der Begriffe“. Man greift also jedenfalls sehr fehl, wenn man Mach in dem Sinne zu den „Empiristen" zuzählen wollte wie etwa John Stuart Mill, dessen Logils nach Machs eigener Aussage mit Unrecht so viel Verbreitung 
in Deutschland gefunden hat und gegen den er sich mit gutem Recht durchaus ablehnend verhält.

Etwas mehr nach der Seite des Empirismus im landläufigen philosophischen Sprachgebrauche neigt K. Pearson, ${ }^{1}$ ) der sich aber immerhin in allen Grundfragen in vollster Übereinstimmung mit Mach befindet, und denselben auch wiederholt als Gewährsmann zitiert. Auch Pearson erwähnt Kant mehrmals, bei dem er eine frühere kritische und eine spätere metaphysische Periode unterscheidet. ${ }^{2}$ )

Näher an Kant steht hingegen der Deutschamerikaner B. Stallo, ein Lehrerssohn aus dem Oldenburgischen, der frühzeitig nach Amerika ausgewandert ist und sich als Autodidakt herangebildet hat. ${ }^{3}$ ) Ursprünglich Hegelianer, ${ }^{4}$ ) war er wohl in der philosophischen Litteratur in eigentlichen Sinne des Wortes mehr bewandert als Mach und Pearson. Er nimmt auch speziell auf Kant öfters und auch mehr in Detailfragen Bezug, wenn auch meistens mehr kritisch als anerkennend. Von den „ontologischen Träumereien Hegels" hat er sich ganz losgesagt, er hofft, die Veröffentlichung seines Erstlingswerkes durch die des bereits genannten Hauptwerkes gesühnt zu haben. Dasselbe erschien 1881, als Stallo das 58. Lebensjahr bereits überschritten hatte, ${ }^{5}$ ) also fast in demselben Lebensjahre seines Urhebers als die Kritik der reinen Vernunft. In diesen zwei äussern Umständen, Aufwachsen in einer metaphysischen Schule und Überwindung derselben an der Schwelle des Greisenalters, stimmen also Kant und Stallo überein. Auch in der Anlage der beiden Werke finden sich Übereinstimmungen: Kant wendet sich gegen die Metaphysik auf dem Gebiete der praktischen Philosophie, Stallo gegen die Metaphysik auf den Gebieten der Mathematik und Physik. Kant untersucht die wirklich stattfindende Erkenntnis, Stallo schickt der eigentlich erkenntnistheoretischen Untersuchung, auf die er selbst das Hauptgewicht gelegt hat, eine für den Physiker bestimmte Darstellung

1) The grammar of science, 1. Auflage London, W. Scott, 1892, 2. Auflage 1901.

2) Als Beispiele eines Metaphysikers führt Pearson u. a. an: „Kant, in his later uncritical period (when he discovered that the universe was created in order that man might have a sphere for moral action!)".

3) Vgl. das Torwort von Mach zu meinèr Übersetzung seines Hauptwerkes "Die Begriffe und Theorien der modernen Physik", Leipzig 1901.

4) Als solcher veröffentlichte er das Buch "The philosophy of nature, Boston, Crosby \& Nichols 1848.

s) Stallo ist am 16. März 1823 geboren. 
voraus, in der er erst dic unvermeidlichen Widersprüche der bisherigen Ansicht aufdeckt. Entgegen den üblichen Anschaunngen der zeitgenössischen Physiker betont er wiederholt die Notwendigkeit erkenntnistheoretischer Untersuchung im Sinne Kants. So hält er schon in der (in die deutsche Ausgabe nicht aufgenommenen) Vorrede zur 2. Auflage, die sich mit der Aufnahme des Werkes von Seite der englisch-amerikanischen Kritik beschäftigt, den modernen Physikern vor, ${ }^{1}$ ) sie wären ,ohne die geringste Ahnung davon, dass nicht nur die theoretische Auswertung der Beobachtungsdaten, sondern Erfahrung selbst unmöglich sei ausser unter Zugrundelegung bestimmter, allgemeiner, unerbittlicher Gesetze der Erkenntnis“. Als solche Gesetze stellt er die der Kausalität, Konstanz und Kontinuität hin. „Das Gesetz der Kausalität ist seinem Wesen nach ein Gesetz der Korrespondenz und Äquivalenz von Veränderungen; seine Wurzel liegt in der durchgängigen Relativität und gegenseitigen Abhängigkeit aller Naturerscheinungen. Es besagt, dass, wo immer auch eine Veränderung einer Erscheinung oder einer Reihe solcher beobachtet wird, wir gezwungen sind infolge der Beziehungen dieser Erscheinungen zu andern, von denen deren Existenz abhängt, nach einer äquivalenten Veränderung in diesen andern Erscheinungen zu suchen. Die Frage nach der Ursache entsteht nur dort, wo eine Veränderung vorliegt; und die gesuchte Ursache ist gleichfalls wieder eine Veränderung. Es erhebt sich natürlich sofort die Frage, was die Kriterien der verlangten Äquivalenz sind - eine Frage, die hier nicht untersucht und mit der einfachen Bemerkung beschieden werden muss, dass diese Kriterien von der Natur der Veränderungen abhängig sind, deren Korrespondenz und Äquivalenz in Betracht stehen." ") „Das Gesetz der Konstanz ist weiter nichts als das Gesetz der Kausalität mit Rücksicht auf die Äquivalenz und gegenseitige Korrespondenz der einander bestimmenden Erscheinungen, wie dies z. B. in der Mechanik an dem Satz von der Gleichheit der .Wirkung und Gegenwirkung zu Tage tritt.“") „Das Gesetz der Kontinuität ist ein anderer Ausdruck des Kausalgesetzes, der sich aus der Thatsache ergiebt, dass alle physischen Veränderungen in Raum und Zeit vor sich gehen, die notwendig als stetig aufgefasst werden müssen. Zu sagen, der Raum sei unstetig, würde

1) The concepts and theories of modern physics, $3^{\text {rd }}$ ed., p. XIX.

2) Ib. p. XXXVIII.

3) Ib. p. XXXIX. 
heissen, dass zwischen zwei benachbarten Punkten es ein räumliches Intervall giebt; und ebenso würde die Behauptung einer Unstetigkeit der Zeit dazu führen, zu sagen, dass es zwischen zwei noch so nahen Momenten ein Zeitintervall gebe." ${ }^{1)}$ Stallo bemerlkt sodann bezïglich „der alten Frage, ob das Kausalitätsgesetz ein Satz a priori oder a posteriori sei", dass dieselbe nach seiner Ansicht nur durch eine Überprüfung der alten Antithese von a priori und a posteriori gelöst werden könne. Ebenso geht aus der ganzen Auffassung im Buche selbst ein merkliches Hinüberneigen zu Kantischen Ansichten hervor. Andererseits bekämpft allerdings Stallo Kants Raumlehre wie seine kosmologische Theorie als metaphysisch und bemerkt von ihm, dass er nicht ohne Grund den Reihen ontologischer Metaphysiker beigezählt worden sei. ${ }^{2}$ )

Gleichfalls merklich von Kant beeinflusst ist auch $\mathrm{H}$. Hertz in seiner nachgelassenen Mechanik. Allerdings berührt derselbe allgemein philosophische Fragen nur indirekt, und auch der Umstand, dess er noch kurz vorher auf dem ïblichen Standpunkt der Physiker gestanden, ${ }^{3}$ ) und seine Mechanik nicht selbst mehr herausgegeben hat, bewirkt in der Ausdrucksweise eine Anlehnung an den gewohnten Sprachgebrauch des Physikers. Ob Hertz sich speziell mit Kant beschäftigt und wie weit überhaupt seine philosophischen Studien gegangen sind, ist - wenigstens aus der Biographie, die seinen gesammelten Werken vorgedruckt ist - nicht ersichtlich; nur so viel ist gewiss, dass er Mitglied der Londoner "Society for psychical researches" war. Den Gedankengang, den er in der Einleitung zu seinen Prinzipien der Mechanik einschlägt, kann man aber unschwer an den der Vernunftkritik anschliessen. Hertz behält noch den Begriff des Dinges an sich bei; da er in seinen weiteren Betrachtungen aber keine Rolle mehr spielt, führt es auch zu keinen Widersprüchen. Hertz sagt: die Dinge, wie sie an sich sind, können wir nicht erkennen, aber - das haben wir auch nicht not. Genug an dem, dass wir nur die Folgen der Dinge, d. i. die Erscheinungen kennen! Die Aufgabe der Physik formuliert daher Hertz in die Worte: "Wir machen uns innere Scheinbilder oder Symbole der äusseren Gegenstände und zwar machen wir sie von solcher Art, dass die denknotwendigen Folgen

1) Ib. p. XXXIX.

2) Ib. p. XXXVI.

3) Man vergleiche z. B. den Schluss der Heidelberger Rede über die Beziehungen zwischen Licht und Elektrizität. 
der Bilder stets wieder dio Bilder seien von den naturnotwendigen Folgen der abgeljildeten Gegenstände." "I) Unsere "Symbole" der änsseren Gegenstände sind Er/cugnisse unseres Geistes, Konstruktionen a priori. Sie müssen als erste Bedingung die erfüllen; dass sic zulässig sind, d. h. den Denkgesetzen unseres Geistes nicht widersprechen. Von ihnen ist eine Wissenschaft a priori im Sinne Kants möglich. Die Frage, ob unsere Begriffe eine Folge blosser Definitionen oder einer apriorischen Anschauung im Sinne Kants seien, lässt dabei Hertz ausdrücklich dahingestellt. ${ }^{2}$ ). Keineswegs ist aber Hertz deshalb der Ansicht Kants - wie ihm von Cohen zugemutet worden ist - , dass der menschliche Verstand im Stande sei, der Natur seine Gesetze vorzuschreiben. Obige Bedingung ist nur eine der notwendigen Bedingungen, denen unsere Begriffe entsprechen müssen, sie ist aber keineswegs eine hinreichende. Unsere Begriffe müssen ferner die zweite ebenso notwendige Bedingung erfüllen, dass sie richtig sind, nämlich dass sie der Erfahrung nicht widersprechen. Ob sie das thun, „kann nur nach dem Stande der gegenwärtigen Erfahrung und unter Zulassung der Berufung an spätere reifere Erfahrung" entschieden werden. Denn „was aus Erfahrung stammt, kann durch Erfahrung wieder vernichtet werden". Man sieht also wieder dasselbe Verhältnis zu Kant wie bei den früher erwähnten Denkern: Beschränkung unserer Kenntnisse auf die Erscheinungswelt, Anerkennung und Hervorhebung der, begriffsbildenden Thätigkeit des Subjektes, Beschränkung der apriorischen Giltigkeit der erzengten Begriffsbilder

1) Hertz, Gesammelte Werke, III. Bd., S. 1.

2) Ebendort, S. 53. Der ganze Anfang des ersten Buches lautet: "Vorbemerkung. Den Überlegungen des ersten Buches bleibt die Erfahrung yöllig fremd. Alle vorgetragenen Aussagen sind Urteile a priori im Sinne Kants. Sie beruhen auf den Sätzen der inneren Anschauung und den Formen der eigenen Logik des Aussagenden und haben mit der äusseren Erfahrung desselben keinen aindern Zusammenhang, als ihn diese Anschauungen und Formen etwa haben. Abschnitt I: Zeit, Raum, Masse. Die Zeit des ersten Buches ist die Zeit unserer inneren Anschauung. Sie ist daher eine Grösse, von deren Änderung die Änderungen der übrigen betrachteten Grössen abhängig gedacht werden können, während sie selbst stets unabhängig veränderlich ist. Der Raum. des ersten Buches ist der Raum unserer Vorstellung. Er ist also der Raum der Euklidschen Geometrie mit allen Eigenschaften, welche diese Geometrie ihm zuspricht. Es ist gleichgiiltig für uns, ob man diese Eigenschaften ansieht als gegeben durch die Gesetze der inneren Anschauung, oder als denknotwendige Folgen willkürlicher Definitionen." 
T̈ant und die naturwissenschaftliche Êrkenntniskritik der Gegèntwart. 301

auf ihre formale Übereinstimmung, Anerkennung der Erfahrung als inappellable Instanz, die zwar die Richtigkeit unserer Begriffskonstruktionen widerlegen, sie aber niemals mit endgiltiger Gewissheit bestätigen, 'd. h. beweisen kann. Nun hebt noch Hertz ausdrücklich hervor, dass die beiden genannten notwendigen Bedingungen auch zusammen noch nicht ausreichend sind, dass vielmehr noch eine dritte Bedingung hinzukommt, die wir an unsere Begriffe stellen müssen, die der Zweckmässigkeit. Es ist das diejenige Eigenschaft unserer Begriffe, die Mach unter dem Gesichtspunkte der Denkökonomie hervorgehoben hat. ${ }^{1}$ ) Mit der Aufstellung dieses Prinzips von fundamentalster Bedeutung, das der Kantischen Erkenntnislehre noch völlig fremd ist und das auch bis jetzt ausser von H.Cornelius, der es in ausgiebigster und meisterhafterWeise verwendet, noch nicht die ihm gebührende Anerkennung gefunden hat, gewinnt die moderne Wissenschaft den Ausgangspunkt zu einer neuen Definition ihres Wesens, die es ihr ermöglicht, auf die alte Platonische, auch von Kant festgehaltene, auf die Allgemeinheit und Notwendigkeit des Wissens gegründete Definition zu verzichten. Das bedingt auch einen wesentlichen Unterschied in der Natur der Wissenschaft. So lange man von der Forderung der Allgemeinheit und Notwendigkeit des Wissens ausgeht, sieht man sich zu einer mechanistischen Auffassung des Denkprozesses hingedrängt, von dem man nach Analogie der Vorgänge in der anorganischen Welt in eindeutiger Weise bestimmte Ergebnisse erwartet, etwa ähnilich wie von einem Automaten. Die Aufgabe der Wissenschaft ist aber in Wirklichkeit gar nicht eindeutig bestimmbar, sie lässt mehrere Lösungen zu. „Eindentig sind die Bilder, welche wir uns von den Dingen machen wollen, noch nicht bestimmt durch die Forderung, dass die Folgen der Bilder wieder die Bilder der Folgen seien. Verschiedene Bilder derselben Gegenstände sind möglich und diese Bilder können sich nach verschiedenen Richtungen unterscheiden". „Das eine Bild kann nach der einen, das andere nach der andern Richtung Vorteile bieten, und nur durch allmähliches Prüfen vieler Bilder werden im Laufe der Zeit schliesslich die zweckmässigsten gewonnen". "Verschiedene Bilder derselben Gegenstände sind

1) Man hat Mach den seltsamen Vorwurf gemacht, dass die Denkökonomie nichts neues sei und schon vor ihm im Denken eingehalten worden ist. Ich glaube, Mach hat auch, gar keinen Anspruch darauf erhoben - ein neues Denken oder gar das Denken schlechthin erfunden zu haben. 
möglich". Damit haben denn Nach und Hertz eine viel weitergehende Freiheit des Denkens anerkannt als selbst Kant, der von ihnen in diesem Punkte wesentlich überholt worden ist.

Eine systematische Entwicklung der erkenntnistheoretischen Grundthatsachen, durch die Erfahrung im modern naturwissenschaftlichen Sime zu Stande kommt nach der Methode Kants, giebt H. Cornelins. ') Sein Ausgangspunkt ist der von Berkeley, Mach und Pearson; als gegeben betrachtet er lediglich Bewusstseinsinhalte, das Ding an sich wird als "naturalistischer" Begriff von vornherein abgelehnt. Dagegen benützt Cornelius die transscendentale Methode Kants zur Ableitung der elementarsten Thatsachen unseres Seelenlebens, die unumgängliche Voraussetzung jeder Erfahrung sein müssen. Zwei wesentliche Momente unterscheiden diese Deduktion von der Kants: erstens wird nicht Erfahrung in einem ganz speziellen Sinne, sondern Erfahrung überhaupt im allerallgemeinsten Siune des Wortes vorausgesetzt, so dass nicht wie bei Kant der Einwand erhoben werden kann, wenn diese Erfahrung auch nicht vorhanden sei, so könne es eine andersgeartete sein; zweitens lassen sich die so als notwendig erschlossenen Thatsachen auch in der unmittelbaren Erfahrung nachweisen, wovon Kant die Möglichkeit geleugnet hatte. Am nächsten schliesst sich diese Ablcitung an die subjektive (in der 2. Aufl. weggelassene) Deduktion der Kategorien an. Zwei wesentliche Momente sind es, welche die Darstellung von Cornelius auszeichnen, und die sonst noch zu wenig beachtet worden sind. Das eine derselbe beruht auf der Betrachtung ganzer Komplexe von Bewusstseinsinhalten im Gegensatze zu den von der atomistischen Psychologie als Ausgangspunkt gewählten psychischen Elementen; ganz richtig bemerkt Cornelius, dass letztere selbst erst durch Analyse von Komplexen erhalten werden. Der zweite Punkt betrifft die wichtige Unterscheidung zwischen Wahrnehmungs- und . Erfahrungsurteilen; erstere beziehen sich auf solche Erfahrungen, die auch ohne den Begriff eines Gegenstandes möglich sind (siehe oben S. 281), letztere auf Erfahrungen im Sinne Kants, wo eive Einordnung unter einen Begriff stattfindet. Im Gegensatze zu Kant lässt jedoch Cornelius denselben mit Mach durch die Erfahrung entstehen; eine neue Erscheinung wird nach einem

1) Psychologie als Erfahrungswissenschaft, Leipzig 1896, S. 1 ff. Einleitung in die Philosophie, Leipzig, S. $204 \mathrm{ff}$. 
Kant und die naturwissenschaftliche Erkenntniskritik der Gegentivart. 303

bereits geläufig gewordenen Zusammenhange gedeutet, es entstehen „Erwartungsurteile“, an denen wir so lange festhalten, bis uns neuartige Erfahrung zu Modifikationen der von uns vorausgesetzten Zusammenhänge veranlasst. Finden wir unsere Erwartung nicht bestätigt, dann stossen wir unsern Begriff „der zweiten Kategorie“ nicht um, sondern trachten durch eine neu hinzutretende Annahme die neue Erfahrung mit den alten in Übereinstimmung zu bringen. Insofern ist der Zweifel Humes an der Giltigkeit des Kausalurteils nicht völlig berechtigt, insofern kann auch auf dem Gebiete der Erfahrung von Urteilen a priori die Rede sein. Die Gegenstände erscheinen so als Regel für die Erscheinungen, durch die erst unsere Erfahrungen in einen Zusammenhang nach Gesetzen verwandelt werden. Ausserdem erkennt Cornelius auch synthetische Urteile a priori an; es sind das jene, die sich aus der Natur der Wahrnehmungsbegriffe ergeben, für die eine Zurückführung anf einfachere Begriffe, also eine Definition deshalb nicht möglich ist, weil sie selbst die einfachsten Begriffe sind. Es sind das also eigentlich analytische Urteile, die nur aus Mangel einer Definierbarkeit des Begriffes nicht als solche erscheinen. Ihr Umfang ist ein anderer als bei Kant, einerseits gehören Urteile hiezu, die Kant nicht als solche anerkannt hat, wie z. B. ,.jede Tonempfindung besitzt die Merkmale der Höhe und Stärke", andererseits sind nicht alle geometrischen Urteile in diesem Sinne synthetische Urteile a priori. Es sind das alles Entwicklungen, die wohl in Einklange stehen mit den sonstigen Anschaungen der naturwissenschaftlichen Erkenntniskritik und die geeignet sind, dieselben nach einigen Richtungen hin $\mathrm{zu}$ vervollkommnen. Cornelius ist bestrebt, dieselben im möglichsten Anschlusse an Kant darzustellen, wie er denn selbst am Schlusse seiner Ausführungen sagt: ${ }^{1}$ ) „Die rein empirische Weltansicht, deren fundamentale Bestimmungen wir uns im vorigen zusammenfassend vergegenwärtigten, ist im wesentlichen identisch mit derjenigen Theorie, welche Kant unter dem Namen des transscendentalen Idealismus in der Kritik der reinen Vernunft aufgestellt und begründet hat. Wenn auch die Absicht der Kantischen Untersuchung sich von vornherein nur auf den Nachweis der Möglichkeit allgemeingiltiger und notwendiger Erkenntnisse richtet, so enthält diese Untersuchung doch alle Elemente, deren konse-

1) Einleitung in die Philosophie, S. 334. 
quente Weiterbildung zu der rein empiristischen Weltansicht führen musste. Spezicll derjenige Teil des Kantischen Werkes, welcher die Lösung der Antinomien zum Gegenstande hat, liefert den unzweideutigen Beweis für die Wesensgleichheit mit dem reinen Eupirismus. Im Widerspruche mit dem letzteren stehen bei Kant nur jene Punkte, auf deren Unvereinbarkeit mit den übrigen Bestimmungen der Kantischen Theorie bereits weiter oben hingewiesen wurde: die Raumlehre der transscendentalen Ästhetik und der gelegentliche positive Gebrauch des Begriffes eines transscendenten Dinges an sich als Grundlage der Erscheinungen. Dass im vorigen die empiristische Weltansicht auf rein psychologischer Grundlage entwickelt wurde, bedingt nur einen scheinbaren Widerspruch zu der erkenntnistheoretischen Untersuchung Kants, der seine Überlegungen durchgängig von psychologischen Voraussetzungen freizuhalten bestrebt ist. Thatsächlich vermag auch er seine Betrachtung doch nur auf psychologischer Grundlage aufzubauen: insbesondere ist die fundamentale Untersuchung der transscendentalen Analytik, die ,Zergliederung des Verstandesvermögens', von Anfang bis zu Ende rein psychologische Analyse." ${ }^{1}$ ) Nehr wie aus andern kann man daher aus dieser Darstellung die nahe Verwandtschaft erkennen, in die sich die Lehren der phänomenologischen Erkenntnistheorie zu der Kants bringen lassen. Durch Abstreifen des Platonischen Wissenschaftsbegriffes kann man in der That 'ziemlich leicht den Übergang von Kants Auffassung der Physik zu der der modernen Erkenntnistheoretiker derselben finden. Ein wesentlicher Unterschied gegen Kant, der hingegen bei Cornelius mehr hervortritt als bei Hertz oder vielleicht selbst bei Stallo, ist sein Verhältnis zum Ding an sich. Wie Mach und Pearson erklärt er den Gegenstand im Sinne eines transscendentalen Idealismus, ohne auf ein Ding hinter der Erscheinung Rücksicht zu nehmen. So lange man bei den Gegenständen der physischen Welt bleibt, führt dies auch zu gar keinen Bedenken. Etwas anders wird die Sache, wenn es sich um den Schluss auf die Existenz fremden Bewusstseins handelt. Dieses

1) In einer beigefügten Fussnote verwahrt sich Cornelius gegen eine Auffassung seines Empirismus als Abart eines solchen, wie ihn etwa J. St. Mill vertritt, der nur einen Teil der psychologischen Thatsache beachte; er teilt also die Abneigung Machs gegen den englischen Logiker. 
Kant und die naturwissenschaftliche Erkenntniskritik der Gegenwart. 305

kann nie Gegenstand unserer Erfahrung werden ${ }^{1)}$.und zwar in einem wesentlich andern Sinne nicht, als etwa unsere Behauptungen über die Beschaffenheit ferner Himmelskörper, die ja alle noch Empfindungsmöglichkeiten bedeuten und in derselben Weise erschlossen werden wie unser Wissen über die Gegenstände unserer näheren Umgebung. Der Schluss auf die Existenz fremden Bewusstseins ist und bleibt hingegen ein metaphysischer. "In der That hindert uns keine unserer Erfahrungen", wie es ja auch bei Cornelius heisst, „die Gesamtheit der uns umgebenden Organismen als rein automatische Maschinen aufzufassen, mit deren Bewegungen keinerlei psychisches Leben verbunden ist und in deren Mitte unser Ich als das einzige Bewusstseinsleben übrig bleibt. Was uns diese empirisch nie zu widerlegende ,solipsistische' Anschauung als eine Ungeheuerlichkeit erscheinen lässt, ist nur die Fremdartigkeit, welche die gesamte belebte Welt durch diese Anschauung erhält, gegenüber der Vertrautheit, die jenen Bewegungen durch die natürliche Deutung in Analogie mit unsern eigenen Bewegungen zuteil wird. Nur durch diese, dem natürlichen Weltbilde geläufige Vorstellung vermögen wir die Gesamtheit der uns umgebenden Organismen unter einen uns bekannten Gesichtspunkt zu fassen; ohne diese Vorstellung würden dieselben uns als etwas höchst Unheimliches, Gespensterbaftes entgegentreten. ${ }^{2}$ ) Das Prinzip der Ökonomie des Denkens ist es auch hier, welches unsere Begriffsbildungen beherrscht: da die vorwissenschaftliche Begriffsbildung diesem Prinzip bereits vollständig und ohne jeden Widerspruch mit der Erfahrung genügt, vermag das wissenschaftliche Denken ihr nichts hinzuzufügen". ${ }^{3}$ ) Man kann mit Mach sagen, dass die Annahme fremder Iche unser Weltverständnis erleichtert; ein transscendenter Schluss bleibt sie doch. Man kann freilich Cornelius zugeben, „dass ein wesentlicher Unterschied zwischen dieser Annahme und jenen metaphysischen Begriffen, gegen deren Existenzberechtigung sich die früheren Ausführungen richteten, besteht. Während das ,Ding an sich' im Sinne der ,unerkennbaren Ursache der Erscheinungen' ein Unvorstellbares und seinem Begriffe nach innerlich Widerspruchsvolles blieb, er-

1) Auch nicht durch die von Pearson vorgeschlagene Nervenverbindung zweier Individuen, was auch Cornelius als undenkbar erklärt.

2) Ein Citat von Cornelius verweist hier auf Avenarius (Der menschliche Weltbegriff, S. 8).

3) Einleitung in die Philosophie, S. $323 \mathrm{f}$.

Kantstudien virr. 
scheint das vorausgesetzte fremde psychische Leben von vornherein als ein unserem Vorstellen vollkommen Zugängliches. Die Aufgabe, den Begriff eines von unserer Wahrnehmung unabhängigen Daseins auf Grund von Erfahrungsthatsachen zu definieren, findet also hier kein Analogon. Während wir jenes Ding nicht als Bewusstseinsinhalt denken dürfen und daher die Frage, wie wir es zu denken haben, da uns doch nur Bewusstseinsinhalte als Vorstellungsmaterial gegeben sind, notwendig gestellt und beantwortet werden musste, können wir uns die fremden Bewusstseinsinhalte von vornherein nicht anders als unter dem Bilde der uns unmittelbar bekannten Thatsachen denken. Sie enthalten also in dieser Hinsicht für unser. Denken keinerlei Problem. Nur dürfen wir uns durch die scheinbare Selbstverständlichkeit dieser Vorstellung nicht verleiten lassen, die Übereinstimmung der fremden Inhalte mit denen unseres eigenen Bewusstseins für gesichert zu halten". Eine Schwierigkeit bleibt aber doch bestehen: nach Analogie unseres Bewusstseins können wir nur eine Bewusstseinsart hinausprojicieren und die genügt offenbar nicht. Einer Pflanze oder einem Steine, aber auch den verschiedenen Tierarten werden wir nicht dasselbe Bewusstsein zusprechen, wie uns selbst. Wo ist da aber die Grenze? Und wie viel Formen des Bewusstseins giebt es? Das alles sind Fragen, über welche die strenge Wissenschaft nie Auskunft wird geben können.

Das Verdienst, diesen Sachverhalt mit wünschenswertester Schärfe betont zu haben, gebührt W. K. Clifford, dem berühmten englischen Nathematiker, Erkenntnistheoretiker und Philosophen. ${ }^{1}$ ) In Bezug auf die erkenntnistheoretische Auffassung der Geometrie und Physik unterscheidet sich Clifford in gar nichts von Mach, Pearson oder Stallo. Als Mathematiker verbreitet er sich hauptsächlich über Geometrie und die mathematische Physik, er bleibt aber dabei nicht stehen. Nicht nur, dass er sich eingehend in bedeutungsvollen Essays über Fragen der Ethik, des Rechtes und der Religion ergeht, so macht er auch an der Grenze zwischen strenger Wissenschaft und Metaphysik nicht Halt, ohne

1) Lectures and essays, 2 Bände, 3. Aufl. London 1901, Seeing and thinking, 2. Aufl. London 1880, The common sense of the exact science, posthum her. u. ergänzt von K. Pearson, 4. Aufl. London 1898, Mathematical Papers, London 1882. Davon sind deutsch erschienen: Über die Ziele und Werkzeuge des wissenschaftlichen Denkens, München.1896 und Von der Natur der Dinge an sich, Leipzig 1903. 
Kant und die naturwissenschaftliche Whrkenntniskritik der Gegentvart. 307

aber aufzuhören, sich derselben bewusst $z u$ bleiben. Die scharfe Bestimmung derselben ist eben eines seiner Hauptverdienste. Sie findet sich in dem zuerst im "Mind“ erschienenen Aufsatz über die „Dinge an sich". Als Gegenstand der Naturwissenschaft bezeichnet er daselbst die Bestimmung der objektiven Orduung meiner Empfindungen; „das Wort ,Objekt' (oder ,Erscheinung') dient dabei lediglich als ein Mittel, um eine Gruppe meiner Empfindungen auszudrücken, die als solche in einer geewissen Hinsicht beständig bleibt"; es „besteht daher nur in einer Reihe von Veränderungen meines Bewusstseins und ist nichts ausserhalb desselben". „Die Schlüsse der Physik sind sämtlich Schlüsse, die sich auf meine wirklichen oder möglichen Empfindungen beziehen; Schlüsse auf etwas in meinem Bewusstsein wirklich oder potentiell Vorhandenes, nicht auf etwas ausserhalb desselben Gelegenes“. „Es giebt indessen Schlüsse, die von denen der physikalischen Wissenschaft von Grund aus verschieden sind. Wenn ich zu dem Schlusse komme, dass D u bewusst bist, und dass es Objekte in Deinem Bewusstsein giebt ähnlich denen des meinigen, dann schliesse ich nicht mehr auf irgend welche wirklichen oder möglichen Empfindungen meiner selbst, sondern auf Deine Empfindungen, die keine Objekte meines Bewusstseins sind, noch auf irgend welche Weise werden können“. „Hingegen führt der Schluss auf Deine Empfindungen, auf objektive Gruppen unter ihnen ähnlich denen unter meinen Empfindungen und auf eine subjektive Ordnung, die in mancher Hinsicht meiner eigenen entspricht, im Akt des Schliessens selbst aus dem Bewusstsein heraus; diese Existenzen werden als ausserhalb desselben liegend erkannt, nicht als ein Teil von mir selbst. Ich schlage demgemäss vor, diese erschlossenen Existenzen Ejekte zu nennen, als Dinge, die aus meinem Bewusstsein herausprojiciert werden, zum Unterschiede von den Objekten als Dingen, die in meinem Bewusstsein als Erscheinungen auftreten". Die Existenz fremder Ichs bedingt nun eine positive Einflussnahme auf die Erkenntnistheorie; an die Stelle des bisherigen "Individualbegriffes" Objekt tritt der "Sozialbegriff" Objekt. Der Begriff von einem Tisch z. B. „bildet das Symbol für eine unendliche Zahl von Ejekten verbunden mit einem Objekt, dem der Begriff eines jeden Ejektes mehr oder weniger ähnlich ist. Sein Charakter ist demnach vornehmlich ejektiv in Bezug darauf, was er symbolisch darstellt, objektiv aber in Bezug seiner Natur. Diesen komplexen Begriff 
werde ich das soziale Objekt nennen; es bildet ein Symbol für ein Ding (das des Unterschieds halber individuelles Objekt genannt werden mag), welches sich in meinem Bewusstsein befindet und fïr eine unendliche Zahl anderer Dinge, welche Ejekte sind und sich ausserhalb meines Bewusstseins befinden". Aus der totalen Verschiedenheit von Objekten und Ejekten schliesst Clifford auf die Unmöglichkeit einer gegenseitigen Wechselwirkung und damit auf die Theorie des Parallelismus. Die Riicksichtnahme auf die Lehre von der Entwicklung der Lebewesen führt ihn dann zur Aufstellung einer eigenen metaphysischen Theorie, die in der $A b$ handlung selbst eingesehen werden mag; für den vorliegenden Zweck ist sie ohne weiteren Belang.

Aus diesen Darlegungen mag ersehen werden, inwieweit und nach welchen Richtungen hin Kants Gedankenwelt auf die Fortentwickelung der Erkenntnistheorie der exakten Wissenschaften von Einfluss war. Es sind dies nicht die einzigen von Kant ausgegangenen Einwirkungen auf das mathematisch-naturwissenschaftliche Gebiet; jeder wird wohl in der obigen Zusammenstellung den Namen Helmholtz vermissen. Es erklärt sich dies aus dem besonderen Zweck dieser Darlegungen; nicht um eine historische Beleuchtung des Kantischen Einflusses schlechtweg, sondern nur um seine Einwirkung auf die Gestaltung jener Erkenntnistheorie, als deren Hauptrepräsentant Mach gelten kann, und die man als phänomenalistische oder empirisch-kritische bezeichnen mag, war es ja hier zu thun. Andererseits fehlen einige wichtige Namen deshalb, weil der Einfluss Kants bei ihnen nicht ersichtlich ist; ich erinnere nur an Maxwell und Kirchhoff.

Zugleich wird aus der obigen Darstellung wenigstens in .ersten Umrissen ersichtlich geworden sein, welche Teile oder welche Richtungen des Kantischen Denkens als positiv wertvoll auch vom Standpunkte der heutigen Erkenntnistheorie der Naturwissenschaft angesehen werden können.

Es ist dies zunächst seine gegen die Giltigkeit und Zulässigkeit der überlieferten ontologischen Begriffe und Argumentationen gerichtete Kritik. So wie Kant auf dem Gebiete der praktischen Philosophie das Unzureichende der ontologischen Beweisführung nachgewiesen, wenden sich die gesamten Forscher der Gegenwart mit ihrer Kritik gegen die unberechtigten ontologischen Voraussetzungen auf dem Gebiete der exakten'Wissenschaften. . Gleichwie Kant deshalb noch immer Metaphysiker geblieben ist, bleibt 
Kant und die naturwissenschaftliche Erkenntniskritik der Gegenwart. 309

das gleiche auch dem modernen Denker noch nicht völlig verwehrt, wie das Beispiel Cliffords lehrt. Die Grenzen liegen allerdings heute wesentlich gegen früher verschoben, was ja in der Natur der Sache begründet ist. Dem heutigen Geschlechte. wird Kant allerdings als Vertreter einer unberechtigten Metaphysik erscheinen. Sonst bestent aber immerhin eine bemerkenswerte Analogie, so dass man wohl mit gutem Rechte der Erkenntniskritik auf philosophischem eine solche auf physikalischem und mathematischem ${ }^{1}$ ) Gebiete parallel zur Seite stellen kann.

Ein zweites in die moderne Auffassung herübergenommenes Bestandstïck der Kantischen Lehre ist die Anschauung von der Idealität der Erscheinungswelt. Die Wissenschaft der Gegenwart ist da allerdings noch über Kant hinaus gegangen und hat sich auf den Standpunkt Berkeleys gestellt; doch war hier historisch. Kant der Vermittler, während die Übereinstimmung mit der Lehre Berkeleys vermutlich erst nachträglich festgestellt worden sein dürfte.

Ein drittes beibehaltenes wichtiges Moment des Kantischen Gedankenkreises ist die Betonung von der Selbstthätigkeit und Freiheit des Denkens. Die Kategorien sind freilich als solche nicht anerkannt worden; aber dass unsere Begriffe Schöpfungen unseres Geistes sind und sich folglich auch nach den Gesetzen desselben richten müssen, sowie dass wir ihnen als unseren Schöpfungen Vorschriften machen können, ist von allen oben angeführten Denkern zugestanden worden. $\mathrm{Ja}$ in der Betonung der Freiheit des Denkens ging die moderne Wissenschaft sogar beträchtlich über Kant hinaus, insofern als sie den Denkprozess nicht als kausal eindeutig bestimmt ansieht, sondern von vornherein eine Mehrdentigkeit der Lösung zugiebt. Besonders bemerkenswert sind in dieser Hinsicht die Ausführungen von Hertz. Ausser der ausdrücklichen Konstatierung der Möglichkeit mehrerer „Bilder“ über denselben Gegenstand kommen noch die Bemerkungen auf S. 45 seiner Mechanik in Betracht, in denen er die Giltigkeit seines mechanischen Grundgesetzes ausdrücklich auf die unbelebte Natar beschränkt. ${ }^{2}$ )

1) Hier kämen insbesondere auch die auf eine Neubegründung der modernen Mathematik durch kritische Läuterung ihrer Grundbegriffe gerichteten Bestrebungen der Weierstrass'schen Schule in Betracht.

2) Im Gegensatze zu Mach, Pearson und Stallo hält Hertz noch an dem Vorurteil, die ganze Physik mechanisch erklären zu können, fest. 
Auch in der Anerkennung eines Apriori ist die moderne Wissenschaft wenigstons nicht auf dem starr verneinendenStandpunkt Humes stehen geblieben, so wenig sie auch den von Kant erhobenen Anspruch gerechtfertigt finden konnte. Aber in einen gewissen anderu Sinne, als es Kant gemeint, kann man auch heute noch von einem „Apriori“, wenn man so sagen darf und will, sprechen. Die allgemeinsten Sätze der Physik sind allerdings nicht in dem Sinne a priori, dass sie als vor aller Erfahrung und unabhängig von derselben bestehend anerkannt werden könnten. Es ist immer möglich, dass spätere Erfahrung sie zu nichte macht, aber praktisch ${ }^{1}$ ) kommt freilich diese Möglichkeit nur höchst selten ins Spiel. Findet sich eine Thatsache, die mit den bisherigen Theoremen nicht in Eiuklang zu bringen ist, so wird der gewöhnliche Weg nicht der sein, einen allgemeinen Grundsatz umzustossen, sondern es wird für diesen Spezialfall eine besondere Modifikation der bisherigen Gesetze zur Erklärung herangezogen werden. Ja es wird unter Umständen sogar die Aussage vorgezogen werden, dass der Grund der Abweichung bisher nicht bekannt geworden sei, wie es gegenwärtig mit der Frage nach der Energiequelle der Radiumstrahlen der Fall ist. Erst wenn sich derlei unerklärliche Fälle mehren würden, sähe man sich zum Verlassen eines bisherigen Grundsatzes veranlasst. Dies war z. B. der Fall, als der Satz von der Konstanz der Wärmesumme (daher Wärme = Stoff) durch die mechanische Wärmetheorie umgestossen wurde. Das Denken trachtet eben immer, wie sich Mach ausdrückt, neue Erfahrungen den alten anzupassen.

Aber noch in einem andern Sinne besitzen die allgemeinsten Sätze der Physik axiomatischen Charakter. Sie sind nämlich zum Teil - wie dies L. Lange durch sein Prinzip der partikulären Determination zuerst hervorgehoben hat ${ }^{2}$ ) - Definitionen. Ich selbst habe bereits bei mehreren Gelegenheiten auf diesen Charakter

Auch Kant geht, wie die „Metaphysischen Anfangsgründe der Naturwissenschaft" beweisen, von derselben Voraussetzung aus. Es ist dies bei seiner Betonung der Bedeutung rein intensiver Grössen einigermassen auffallend.

1) "Praktisch" ist hier natürlich im gewöhnlichen Sinne des Wortes, nicht aber etwa in dem gemeint, wo von einer "praktischen Philosophie“ gesprochen wird.

2) Die geschichtliche Entwickelung des Bewegungsbegriffes, Leipzig 1886; Über das Beharrungsgesetz, Ber. d. kgl. sächs. Ges. d. Wiss. 1885; Das Inertialsystem vor dem Forum der Naturforschung. Kritisches und Antikritisches. Philos. Studien, Bd. XX (Wundtfestschrift), Leipzig 1902. 
Kant und die naturwissenschaftliche Erkenntniskritik der Gegenwart. 311

der obersten Sätze der Physik (Energieprinzip, Coulombsches Gesetz, Trägheitssatz) hingewiesen.1) Das Trägheitsgesetz ist z. B. so lange Definition, bis es die Begriffe "gradlinig" und „gleichförmig" definiert hat. An und für sich kann jede Bewegung geradlinig und jede gleichförmig heissen. Erstere Möglichkeit reicht, wie L. Lange gezeigt hat, bis zur Dreizahl, d. h. in Bezug auf drei Punkte ist das Trägheitsgesetz immer giltig, weil es Sache blosser Definition ist; erst in Bezug auf einen vierten Punkt erhält es die Bedeutung einer Aussage über Thatsachen, d. h. die Bahn eines vierten Punktes kann nicht mehr in Bezug auf das durch die drei ersten definierte Koordinatensystem nach Belieben als krumun- oder gradlinig aufgefasst werden. Ähnlich verhält es sich in Bezug auf die Zeit: In Bezug auf die Bewegung eines Punktes ist das Gesetz blosse Definition, d. h. ein Punkt bestimmt durch seine Bervegung erst den Begriff gleicher Zeiten, - wie schon Maxwell hervorgehoben hat - in Bezug auf einen zweiten Punkt sagt dann das Gesetz aus, dass seine Dislokationen denen des ersten proportional sind. Erst diese zweite Aussage lässt sich durch die Erfahrung prïfen; die erste ist als Definition selbstverständlich und daher von aller Erfahrung unabhängig. Ähnlich verhält es sich auch mit denı Energiegesetz; die Möglichkeit seiner Aufstellung beruht auf gewissen Thatsachen, ein eigentliches Naturgesetz ist es aber gar nicht, insofern gerade umgekehrt der Begriff der Energie so konstruiert wird, dass dem Gesetze Genüge geschieht. So wird eine Wärmemenge als Energie aufgefasst, wiewohl Wärmemenge und mechanische Energie nicht wirklich gleich oder in allem gleichartig, sondern nur in einer Beziehung einander äquivalent sind. ${ }^{2}$ ) In der Elektrizitätslehre wird der Definition der Masseinheiten von vornherein der Energiebegniff zu Grunde

1) Über das Prinzip der Erhaltung der Energie, Zeitsch. f. phys. chem. Unter. von Poske, 1899, S. $267 \mathrm{ff}$; Z Zur Formulierung des Trägheitsgesetzes, Arch. f. system. Philos. VI. Bd., 1900, S. $461 \mathrm{ff}$.; Über die wahre Bedeutung des Prinzips von der Erhaltung der Energie, Beilage zur Münchner Allgemeinen Zeitung v. 16. Juli 1902; Über Volkmanns „Postulate, Hypothesen und Naturgesetze und deren Beziehung zur phänomenologischen Naturauffassung im Sinne Machs", Ostwalds Annalen der Naturphilosophie, II. Bd. 1903, S. $464 \mathrm{ff}$.

2) Manche Physiker wie z. B. Stefan gebrauchten bei den Gleichungen der mechanischen Wärmetheorie statt des Gleichheitszeichens ein besonderes Äquivalentzeichen. Es ist aber allerdings Gleichheit niemals Identität, sondern stets eine Art von Äquivalenz. 
gelegt, so dass es infolgedessen ein besonderes mechanisches Äquivalent der Elektrizität nicht giebt. Energie darf dabei allerdings, wenn der Satz seine Giltigkeit behalten soll, nicht als Fähigkeit, Arbeit zu leisten, definiert werden; es muss ein mathematischer Begriff bleiben, der nur das Stattfinden einer Äquivalenz behauptet, falls eine Energieverwandlung stattfindet. ${ }^{1}$ )

Die Bedeutung der obersten Naturgesetze ist somit, wie ich an einer frïheren Stelle ${ }^{2}$ ) ausgefïhrt habe, die folgende: "Man kann also zusammenfassend sagen, dass das Trägheitsgesetz und analog die anderen ,Axiome oder Postulate teilweise definierend wirken, dass sie nämlich gewisse Begriffe vorerst definieren, dass aber ihr Inhalt sich nicht mit der Schaffung dieser Definitionen erschöpft, sondern, indem das Gesetz die allgemeine Anwendbarkeit dieser Begriffe behauptet, eine Aussage enthält, deren Zutreffen experimentell kontrollierbar ist. Solche Sätze haben also eine Giltigkeit, die teilweise durch die Erfahrung prüfbar ist, d. h. sie können nicht jeder Erfahrung gegenüber bestehen bleiben, wohl aber ist es möglich, einzelne Erfahrungen mit diesen Sätzen hinterher in Einklang zu bringen durch Schaffung neuer Sätze von speziellerem Charakter. 'Den eigentlichen Prüfstein auf den Wert solcher Sätze bildet erst die Möglichkeit bezw. Unmöglichkeit der Ableitung eines Systems, oder besser ausgedrückt, der Auffïhrung eines Systems auf den von ihnen gelieferten begrifflichen Grundla'gen. In diesem Sinne entscheidet erst fortgesetzte Erfahrung, die unmittelbar die Richtigkeit speziellerer Sätze bestätigt oder widerlegt, über den Wert dieser allgemeinsten physikalischen Grundsätze. Sie erweisen sich als brauchbar, wenn die durch die Erfahrung bestätigten besonderen Sätze sich mit diesen in ein System einordnen lassen, in dem die "Postulate" eben die umfassendste allgemeinste Bedeutung besitzen."

Von einem Apriori im Sinne Kants kann also freilich auch bei den allgemeinsten Grundsätzen der Physik keine Rede sein. Sie unterscheiden sich auch nur graduell und nicht prinzipiell von den speziellen Sätzen der Physik. Jeder derselben tritt einem noch spezielleren Satze gegenüber in axiomatischer Bedeutung in dem hier angedeuteten Sinne auf. Immerhin kommt aber diese Auffassung der Kants insofern entgegen, als sie die Möglichkeit

1) Näheres hierüber findet sich in meinen oben zitierten Schriften.

2) Ostwalds Annalen der Naturphilosophie, II. Bd., S. $113 \mathrm{f}$. 
und Berechtigung einer deduktiven Behandlungsart der Physik nachweist. Vielleicht, dass sich Kant mit ihr zufrieden gegeben hätte, wenn man ihm die Unstatthaftigkeit seiner Auffassung des Apriori nachgewiesen haben würde; erfüllt sie doch einen seiner Lieblingswünsche, indem sie den Nachweis für die Möglichkeit einer wissenschaftlichen Behandlungsart der Physik in seinem Sinne erbringt!

\section{Der Fortschritt der modernen Erkenntnistheorie über Kant hinaus.}

Kant hatte sich die Aufgabe gesetzt, die Philosophie nach dem Muster der exakten Wissenschaften zu reformieren. Zu diesem Zwecke musste er zunächst den Mechanismus der Erkenntnis in den exakten Wissenschaften feststellen.

Die wissenschaftliche Forschung der Gegenwart ist bei der von Kant gegebenen Erklärung für die Möglichkeit dieser Wissenschaften nicht stehen geblieben, sie hat dieselbe nicht als feststehende Errungenschaft anzuerkennen vermocht, sondern sie einer neuen Revision unterworfen.

Das Ergebnis derselben war in der That die Feststellung von der Unhaltbarkeit der Kantischen Position.

Der Hauptgrund hiervon war der, dass Kant von der Platonischen Definition der Wissenschaft ausgegangen war, d. h. von der Voraussetzung, dass nur das Anspruch auf den Namen einer Wissenschaft erheben könne, was allgemein und notwendig giltig sei. Die moderne Wissenschaft hat nun den Nachweis erbracht, dass ein solches Wissen auf dem weiten Gebiete der Naturwissenschaften nirgends $\mathrm{zu}$ finden sei ${ }^{1}$ ) deutlicher aber noch als $\mathrm{zu}$

1) Diese Konstatierung ist als unabänderliche Thatsache und nicht etwa als blosse Ansichtssache anzusehen, die je nach dem Standpunkt des betrachtenden Philosophen bejaht oder geleugnet werden könnte. Jeder physikalische Satz enthält auch eine Prophezeihung für die Zukunft, es ist somit möglich, seine Richtigkeit durch zukünftige Erfahrung zu kontrollieren. Über letztėre können wir aber a priori gar nichts aussagen, weil sie unabhängig von uns eintritt, wir ihr daher nichts vorschreiben können. Die Überzeugung von der Richtigkeit dieses Verhältnisses ist hauptsächlich durch die historisch-kritischen Untersuchungen Machs (Mechanik, Wärmelehre) Gemeingut der physikalischen Welt geworden; wer dieselbe etwa anzweifeln möchte, müsste hier den Hebel ansetzen. Blosse Behauptungen einer angeblichen logischen Unmöglichkeit sind, wie die Geschichte der Philosophie zur Genüge lehrt, eine ebenso billige als wertlose Ware. 
Kants Zeit hat sic durch ihre blosse Existenz den Beweis ihrer Berechtigung geliefert; ganz so wie damals kann man heute sagen, die Naturwissenschaft bedarf knines Beglaubigungsschreibens ron Seite der Philosophie; Aufgabe der letzteren ist es, diesen Zwiespalt zu beseitigen, d. h. die Möglichkeit einer Naturwissenschaft erkenntnistheoretisch zl erklären.

Die Lösung dieser - echt Kantischen - Aufgabe im positiven Sinne hat nun die Erkenntnistheorie Machs zuwege gebracht. Insofern kann man sagen, dass Mach dasjenige geleistet hat, was Kant gewollt und nicht vermocht; er ist in diesem Sinne auf dem Gebiete der Erkenntnistheorie der Naturwissenschaft der Vollender Kants.

Die alte Platonische Definition der Wissenschaft hat sich mit dem Sturze des letzten ihr noch von Kant zugestandenen Apriori als gänzlich umfangslcer erwiesen; sie ist dadurch bedeutungslos geworden, und es galt nun eine neue Definition der Wissenschaft zu finden.

Die Behauptung von der Existenz „allgemeiner" und „notwendiger" Wahrheiten bot ja auch frïher dem Zweifel Raum; allgemein - für wen?, notwendig - für wen? Im absoluten Sinne hatten diese Worte ja schon frïher keine Bedeutung, immer musste doch mindestens hinzugefügt werden: "für den Denker". Wo aber die Grenze zwischen Denker und Nichtdenker gelegen, war nicht ausgemacht. Es war dies ein theoretischer Mangel der alten Definition; praktisch hatte er allerdings weniger Belang.

Es ist aber wichtig den Gedanken festzuhalten, dass der Begriff einer an und für sich seienden, vom Subjekte unabhängigen, objektiv verbindlichen gleichsam über Menschen und Göttern thronenden "göttlichen" Wahrheit ein bedeutungsloser ist. Wahrheit muss zur Erkenntnis des Menschen in Beziehung stehen; eine solche, wie die eben genannte, bliebe ewig unerkennbar; sie ist somit sinnlos. Die Wissenschaft darf daher auch nicht als Inventarium solcher Sätze angesehen werden. Es darf eben nicht vergessen, werden, dass die Wissenschaft eine Schöpfung des menschlichen Geistes ist, und dass sich: die Beziehung anf das Subjektive nie aus ihr loslösen lässt. Die Wissenschaft entsteht durch die Thätigkeit des Subjektes; sie ist ein Kunstprodukt des Menschengeistes; es muss somit von ihr gelten, was von Menschenwerken - mögen sie mehr mit der. Hand oder mehr mit dem 
Kant und die naturwissenschaftliche Erkenntniskritik der Gegenwart. 315

Geiste geschaffen sein - überhaupt gilt: sie muss vor allem einen Zweck haben.

Das erkannt und die Wissenschaft damit in eine Reihe mit den Werken der Technik gestellt zu haben, ist eines der prinzipiellen Verdienste von Mach. Es fragt sich nun, welches ist der Zweck der Wissenschaft? Auf diese Frage hat Mach die Antwort gegeben: Wissenschaft hat den Zweck, uns direkte Erfahrung zu ersparen. ${ }^{1}$ )

Um den Sinn dieser Definition richtig zu erfassen, müssen wir bedenken, dass uns nur einc wirkliche, unmittelbare Quelle naturwissenschaftlicher Erkenntnis zu Gebote steht, nämlich die direkte Erfahrung, das Wort natürlich nicht im Kantischen, sondern im gewöhnlichen Sinne genommen. Es scheint, dass das Verständnis dieser einfachen T'hatsache noch in vielen philosophischen Kreisen auf Schwierigkeiten stösst. Nur so finde ich wenigstens die völlig verständnislose Art einigermassen erklärlich, mit der erst vor kurzem in einem Ferienkurs für Volksschullehrer, der auch nachträglich im Drucke erschienen ist, über die Machsche Philosophie abgeurteilt worden ist. $\left.{ }^{2}\right)$ Die Gewissheit der unmittelbaren Erfahrung ist allerdings auf den Augenblick und das Individuum beschränkt, sie muss sorgfältig von Zuthaten subjektiver Natur geschieden werden, und ist sogar, was obigem Philosophen als besonders schrecklich und schauderhaft vorkam, dem Nenschen mit dem Tiere gemeinsam. Und doch ruht auf ihr einzig und allein der ganze stolze Bau der Naturwissenschaft der Gegenwart! So unscheinbar auch diese Gewissheit dem kühnen Philosophen erscheinen mag, wir müssen uns mit ihr zufrieden geben - einfach deshalb, weil wir keine andere haben. Ein einfaches Beispiel genügt übrigens, um in drastischer Weise den' Wert derselben zu illnstrieren und gegenteilige Befürchtungen zunichte zu machen. Eine Eisenbahnbrücke ist gebaut worden und soll dem Verkehr

1) Im folgenden ist unter Wissenschaft in erster Linie an Naturwissenschaft zu denken. Inwieweit sich der entwickelte Begriff auch weiter ausdehnen lässt, kann hier unerörtert bleiben, da es dem Zwecke obiger Auseinandersetzungen fern liegt. Wünschenswert wären Äusserungen von Forschern auf andern Gebieten über die Möglichkeit dieser Ausdehnung bezw. Vorschläge neuer Definitionen für die betreffende Wissenschaft.

2) Das Ansehen solcher Ferienkurse zu heben, tragen allerdings derlei Publikationen nicht bei. Man muss ja nicht alles lesen - aber auch nicht über alles schreiben. 
ïbergeben werden. Was macht der Staat, um sich von der Richtigkeit ihrer Konstruktion zu ïber'zeugen? Er ruft weder einen Philosophen noch auch einen Sachverständigen; er zieht es vor, über die neue Brücke einen Zug aus lauter Lokomotiven fahren und die einfache ordinäre Empfindung des Zusammenstürzen- oder Nichtzusammenstürzensehens - nıan könnte auch sagen eine besondere Art von Schallempfindung - ihr Gutachten über die Denkarbeit des Ingenieurs abgeben zu lassen! So wie hier der Staat, verhält sich auch der Physiker in seinem Laboratorium; in beiden Fällen kann allerdings die Erfahrung nur nach der negativen Seite hin in abschliessender Weise ihr Urteil fällen.

Freilich, "wie wenig das zu bedeuten hätte, was der Einzelne auf diesem Wege allein in Erfahrung bringen könnte, wäre er auf sich angewiesen, und müsste jeder von vorn beginnen, davon kann uns kaum jene Naturwissenschaft eine genug demütigende Vorstellung geben, die wir in einem abgelegenen Negerdorfe Zentralafrikas antreffen möchten, denn dort ist schon jenes wirkliche Wunder der Gedankenïbertragung thätig, gegen welches das Spiritistenwunder nur eine Spottgeburt ist, die sprachliche Mitteilung." 1 )

Um also unsere eigene direkte Erfahrung, die also allein wirklich gewisse Daten liefert, zu ergänzen, treiben wir Wissenschaft. Sie hat den Zweck, uns fremde Erfahrungen, ja auch unsere eigenen aus früheren Zeiten nutzbar zu machen. Daraus ergiebt sich denn die fundamentale Bedeutung des Machschen Prinzipes der Denkökonomie. ${ }^{2}$ ) Wenn es Zweck der Wissenschaft ist, uns direkte Erfahrungen zu ersparen, so muss offenbar jene Wissenschaft den Vorzug erhalten, welche das Geschäft am grïndlichsten besorgt. Unter den verschiedenen Wissenschaften ist dies die Nathematik. Nirgends findet sich die Denkökonomie so ausgeprägt wie gerade hier. Vom Einmaleins angefangen bis zur Berechnung von Integralen und Auflösung von Differentialgleichungen beruht alles auf der Verwertung bereits gesammelter Erkenntnisse. Das Addieren und Multiplizieren mehrziffriger Zahlen wird auf das der einziffrigen zurückgeführt, d. h. die Resultate des letzteren

1) Mach, Pop. wiss. Vorles. 3. Aufl. S. $264 \mathrm{f}$.

2) Man hat gegen Mach den sonderbaren Vorwurf erhoben, dass dieses Prinzip nichts "Neues" sei und schon längst im Denken Beachtung gefunden habe. Ich glaube indes nicht, dass Mach den Anspruch erhoben hat, das Denken erst erfunden zu haben. 
Kant und die naturwissenschaftliche Erkenntniskritik der Gegenwart. 317

Rechnens werden einfach auswendig gelernt, um dann die des ersteren auf Grund dessen angeben zu können. Jede Rechnungsart mit mehrstelligen besonderen Zahlen liesse sich auch durch direktes Zählen erledigen. Statt dessen tritt das abgekürzte Verfahren auf Grund der bereits erworbenen Kenntnisse über einziffrige Zahlen ein.

Aus diesem Grunde ist es auch das Bestreben der Wissenschaft, „zu suchen den ruhenden Pol in der Erscheinungen Flucht", oder wie sich Jevons ${ }^{1}$ ) ausdrückt: "Die Wissenschaft entsteht aus der Entdeckung von Identitäten im Verschiedenen". Das Streben nach dem Substanzbegriffe ist ja eine charakteristische Eigentümlichkeit des menschlichen Denkens seit Thales' Zeiten. Es erklärt sich durch das Ökonomieprinzip, denn es bedingt eine grosse Vereinfachung in der Beschreibung der Thatsachen. Die Natur der Erklärung besteht in einer auf diese Weise ermöglichten zusammenfassenden Beschreibung; das Gefühl der Befriedigung, das auf diese Weise erreicht wird, erklärt das Vergnügen des Geistes, das derselbe über die Erklärung empfindet.

Nun lässt auch die Frage eine Beantwortung zu, inwiefern die Wissenschaft auf allgemeine und notwendige Giltigkeit Anspruch erheben kann. Ihre Sätze gelten für alle jene notwendig und allgemein, die ihre Voraussetzungen acceptieren. Zu letzterem kann niemand gezwungen werden; wer aber die Grundgesetze des Denkens und eine Reihe beobachteter Thatsachen als erwiesen annimmt, für den haben auch die sich hieraus in deduktiver Weise ergebenden Folgerungen notwendige Giltigkeit. Das war ja schon das Prinzip des Verfahrens von Sokrates, es ist heute das Prinzip jeder exakten Wissenschaft.

Nan sieht, dass man durchaus nicht genötigt ist, mit Hume auf den Begriff einer Wissenschaft auf dem Felde der Thatsachenwelt zu verzichten. Nan kann die volle Berechtigung des 'deduktiven Verfahrens anerkennen, ohne die des induktiven geringschätzig ansehen zu müssen. Beide verhalten sich nach einem nicht unpasssenden Vergleich von Jevons ${ }^{2}$ ) wie Addition und Subtraktion $\mathrm{zu}$ einander.

Die Wissenschaft ist also ein Mittel, um zum Wissen $z \mathfrak{u}$ gelangen. Ihre Eignung zu diesem Zwecke entscheidet über

1) Principles of science, 1. Bd., London 1900, S. 1 .

2) Principles of science, London 1900, S. 121. 
ihren Wert. Von zwei 'Theorien über dasselbe Thatsachengebiet, sagen wir \% B. von zwei Bildern der Mechanik, etwa dem klassischen und dem energetischen, hat jenes höheren Wert, welches auf die cinfachere Weise uns die Kenntnis der mechanischen Thatsachen vermittelt. Dass dabei beide Bilder logisch zulässig und richtig sein müssen, versteht sich von selbst; diese Bedingungen bestimmen jedoch eine 'l'heorie noch nicht in eindeutiger Weise. Gerade diese Müglichkeit verschiedener Bilder ïber dasselbe 'Thatsachengebiet ist ein der Kantischen und aller bisherigen Erkenntnistheorie durchaus fremder Gedanke. Sie war es ja, die immer die Wahrheit als eine und notwendige hingestellt hatte. Das trifft nicht $\mathrm{zu}$, wie die heutige Gestalt der physikalischen Wissenschaft schon zu Genïge erkennen lässt und wie sich auch aus der Freiheit unseres Geistes ergiebt. Das Denken ist eben kein Nechanismus. Der Zweckbegriff spielt beim Denken gerade so seine Rolle als bei der Herstellung von Werken der Technik. Die Thätigkeit des menschlichen Geistes erscheint bei Nach noch weit mehr betont als bei Kant. Die Begriffe sind Mach Anweisungen zur Nachbildung der Thatsachen in Gedanken: Dadurch nun, dass Mach bei der Erklärung des Wesens der Wissenschaft dasselbe in der Thätigkeit und nicht in einem toten Sein erblickt, entgeht er dem Dilemma, dem Hume verfallen ist, entweder die Giltigkeit apriorischen Wissens zuzugestehen oder auf das Vorhandensein strenger Wissenschaft $\mathrm{zu}$ verzichten. Die Wissenschaft ist nicht unsere Herrin, sondern Dienerin; ein Werkzeng in der Hand des rastlos schaffenden Menschengeistes. Die Natur dieses Werkzenges zu ergründen, die Erforschung aller jener Thätigkeitsarten, deren der menschliche Geist fähig ist, um Thatsachen in Gedanken nachbilden zu können, überhaupt die genauere Verfolgung der Prozesse, durch welche die Wissenschaft ihre Aufgabe erfüllt, bleibt ein würdiger Gegenstand der philosophischen Forschung. Nie wird man freilich sagen können, dass die Art der Erkenntnis, die wir durch die Vermittlung der Wissenschaft empfangen, 'von einer höheren Art sei als die unmittelbare Erfahrung; als mittelbare Erkeuntnis muss eine "bewiesene" Thatsache stets linter einer unmittelbaren Thatsache zurïckstehen; hängt doch ihre Anerkennung von der einer Reihe von Voraussetzungen ab, die zur Führung des Beweises nötig waren, so dass der apodiktischen Gewissheit demnach immer ein geringerer Grad von Gewissheit zuzuschreiben sein wird als der assertorischen. "Grau ist alle Theorie ..." sagt 
Kant und die naturwissenschaftliche Erkenntniskritik der Gegeniwart. 319

schon der erste Vertreter der phänomenalistischen Weltanschauung, der Dichter jener herrlichen Fauststelle, die in wenigen Versen ein Entwickelungsbild der gauzen Menschenphilosophie entwirft:

„Geschrieben steht: Im Anfang war das Wort.

Hier stock ich schon! Wer hilft mir weiter fort?

Ich kann das Wort so hoch unmöglich schätzen,

Ich muss es anders übersetzen,

Wenn ich vom Geiste recht erleuchtet bin.

Geschrieben steht: Im Anfang war der Sinn.

Bedenke wohl die erste Zeile,

Dass deine Feder sich nicht übereile!

Ist es der Sinn, der alles wirkt und schafft?

Es sollte stehen: Im Anfang war die Kraft!

Doch, auch indem ich dieses niederschreibe

Schon warnt mich was, dass ich dabei nicht bleibe.

Mir hilft der Geist! Auf einmal seh ich Rat,

Und schreibe getrost: Im Anfang war die That."

Da aber der Umfang jenes Wissens, das wir auf direkte Art erhalten, ein minimaler ist, ja dasselbe in dem Momente seines Entstehens wieder verschwindet, so ergiebt sich hieraus ohne weiteres die unumgängliche Notwendigkeit des koustruktiv-deduktiven Verfahrens. Jedes mittelbare Wissen ist nur unter Annahme gewisser Grundvoraussetzungen richtig. Die unmittelbare Erfahrung kann nur deren Unrichtigkeit. aber nicht deren Richtigkeit erweisen. Was uns die Wissenschaft leistet, besteht nun darin, dass sie die Konsequenzen aüs gewissen Annahmen entwickelt, über deren Richtigkeit oder Unrichtigkeit sie allein nichts ausmachen kann und die innerhalb gewisser Grenzen willkürlich sind. Die Wissenschaft sagt uns: Wenn Du das oder jenes zugiebst, musst $\mathrm{Du}$ auch dieses als wahr erkennen. Die Wissenschaft, die dies thut, ist eine rein deduktive. Darin liegt die Erklärung der Möglichkeit der Mathematik, Geometrie und mathematischen Physik vom Standpunkte der heutigen Erkenntniskritik dieser Wissenschaften.

Es ist daher ein blinder Eifer, wenn so oft von philosophischer Seite gegen den "Phänomenalismus" oder "Positivismus" oder "Relativismus" im guten Glauben, dass derselbe alle „wahre“ Wissenschaft unmöglich mache, Stellung genommen wird und dabei noch meistens in einer ganz verständnislosen Art und Weise. Der leidige Drang alles $\mathrm{zu}$ rubrizieren und $\mathrm{zu}$ klassifizieren mag es wohl verschuldet haben, dass bei einem jeden naturwissenschaftlichen Denker an Empirismus und bei Empirismus an Bacon oder 
J. St. Mrill gedacht wird. Dann ist es freilich auch richtig, dass auf naturwissenschaftlicher Seite - früher wie jetzt - oft unter Aufwand grossen Selbstbewusstseins Ansichten zu Tage treten, die allerdings nur zu geeignet sind, eine von dieser Seite kommende Philosophie gründlich zu diskreditieren. Viele sagen auch, das sei schon alles digewesen zu Heraklits und der Sophisten Zeiten und habe sich nicht bewährt. Erstere Behauptung mag ja einen Kern der Wahrheit in sich bergen, letztere ist nichts weiter als eine

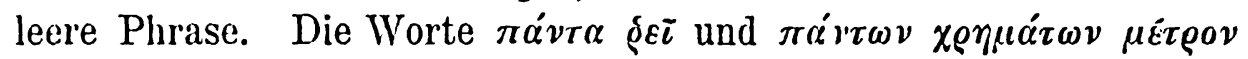

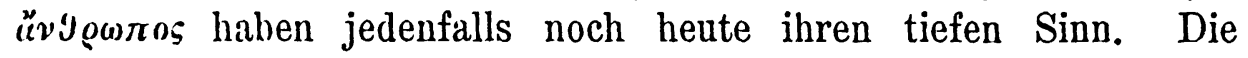
Diskussion in Platons Theätet wird allerdings einer Revision und einer neuen Lösung zugeführt werden müssen; der zweitausend Jahre alte Begriff der Wissenschaft hat in unseren Tagen seine Existenzlerechtigung verloren.

Das ändert aber nichts an der Lebenskraft der Philosophie. Gerade in unseren Tagen stehen ihr neue und wichtige Aufgaben bevor, ein reiches Arbeitsfeld liegt vor ihr. Auf sehr vielen Gebieten ist die heutige Naturforschung so weit vorgedrungen, dass ihr ein weiterer Fortschritt ohne eingehende erkenntniskritische Selbstbesinuung nicht mehr möglich ist. Nur aus diesem Grunde hat sich wohl z. B. Hertz oder Kirchhoff mit Fragen dieser Art beschäftigt. Mit Unrecht wirft man Mangel an philosophischem Verständnis der Gegenwart vor; eben weil sie philosophisch ist, hat sie die Phantasiegebilde des nachkantischen Idealismus in das Reich der Schatten verwiesen. Mit "Kinderstubenerfahrung" wird man allerdings nirgends weiter kommen, auch nicht in der Philosophie. Früher hat ja der Philosoph das gesamte Wissen seiner Zeit umfasst, heute ist dies allerdings unmöglich. Aber ein Verständnis nicht nur der Resultate, sondern auch der Forschungsweise einiger positiver Wissenschaften wird sich heute nicht mehr ungestraft vermissen lassen. Möge der Name Kants, in dessen Zeichen die Philosophie noch heute grösstenteils steht, von günstiger Vorbedeutung sein für eine erneute Verbindung mit der exakten Wissenschaft, für eine neue Reform der Philosophie! 